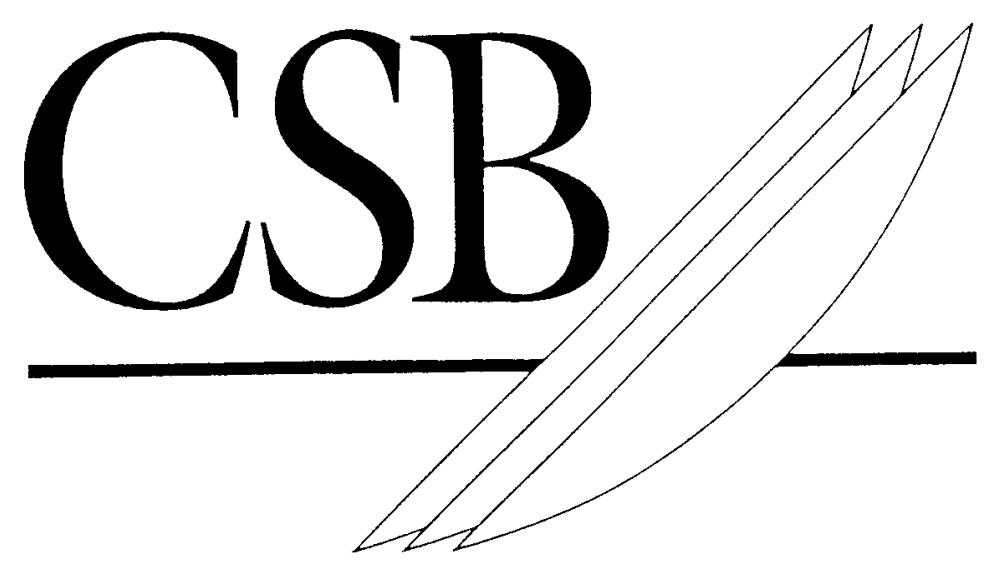

\title{
Maternal employment: the impact of triple rationing in childcare in Flanders
}

\author{
Dieter Vandelannoote* \\ Pieter Vanleenhove** \\ André Decoster** \\ Joris Ghysels** \\ Gerlinde Verbist*
}

April 2013

We are grateful to the participants of the IMPROVE workshop at CHILD in Turin, 1 October 2012, of the Microsimulation research workshop in Bucharest, 11-12 October 2012 and of the PE-ETE seminar in Leuven, 15 November 2012. The usual disclaimer applies.

$\begin{array}{llllllllll}\mathrm{B} & \mathrm{E} & \mathrm{R} & \mathrm{I} & \mathrm{C} & \mathrm{H} & \mathrm{T} & \mathrm{E} & \mathrm{N}\end{array}$




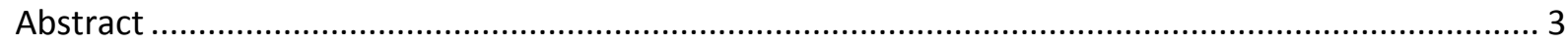

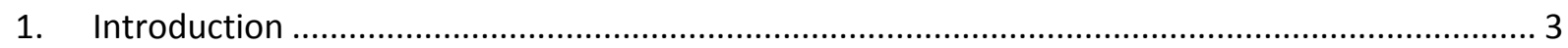

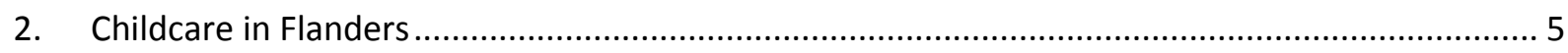

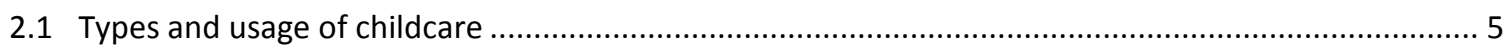

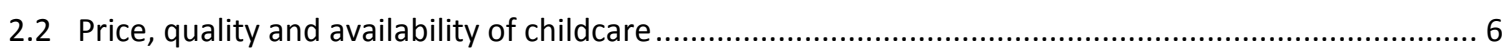

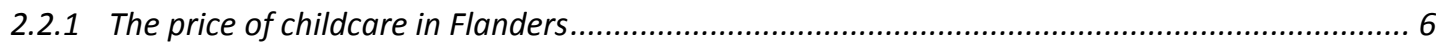

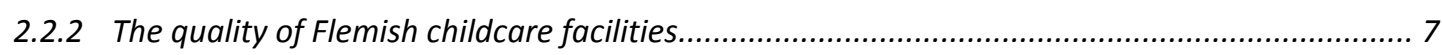

2.2.3 Triple rationing in the Flemish childcare market................................................................ 8

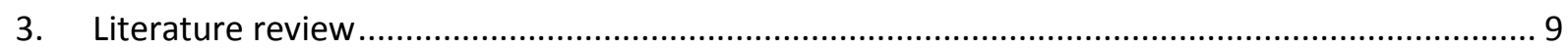

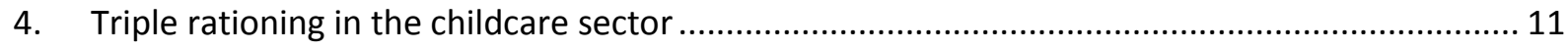

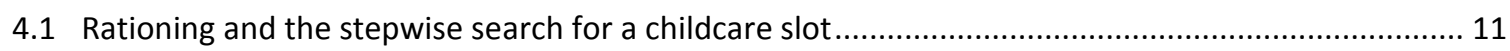

4.2 Rationing estimation through partial observability models............................................................ 12

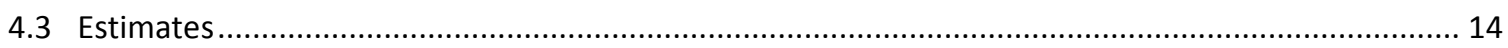

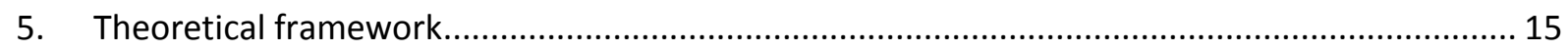

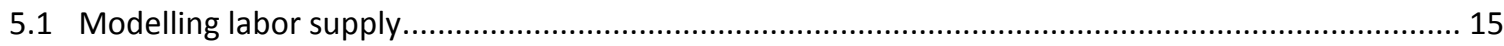

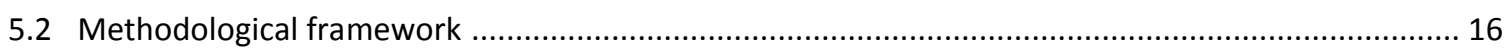

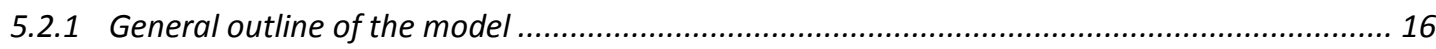

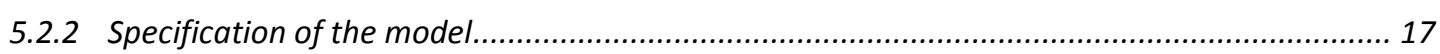

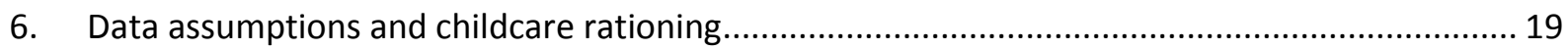

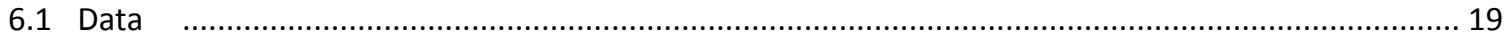

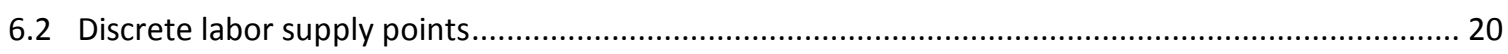

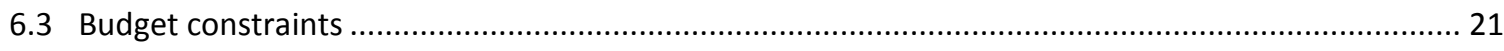

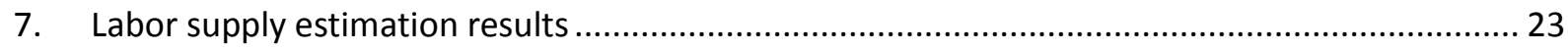

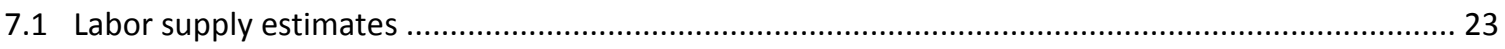

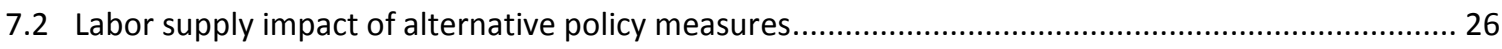

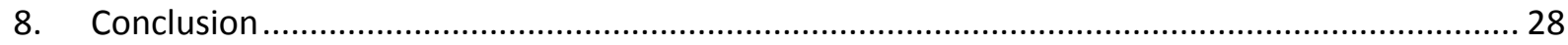

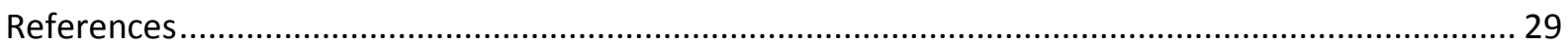

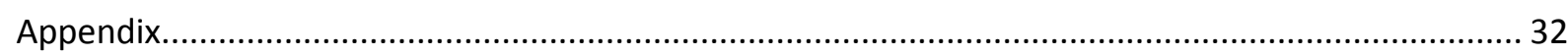

\footnotetext{
*Herman Deleeck Centre for Social Policy, University of Antwerp

${ }^{* *}$ Centre for Economic Studies, KU Leuven

${ }^{* * *}$ TIER, University of Maastricht
} 


\section{Abstract}

This paper analyses how maternal labor supply responds to the price and availability of childcare services. It focuses in particular on the childcare market of Flanders, which is characterised by above average childcare use, a wide variety of price schemes and suppliers, and strong government supervision regarding quality.

Variation in prices and the degree of rationing of three types of childcare services at the municipal level are used to identify mothers' labor supply responses. A discrete labor supply model of the Van Soest (1995) type is elaborated to allow for heterogeneity in prices and to distinguish between rationed and non-rationed households. These extensions rest on rationing probabilities that are estimated separately for informal childcare, formal subsidised childcare and formal non-subsidised childcare using partial observability models (Poirier, 1980).

The estimates confirm earlier findings for Germany and Italy, indicating only small price effects and relatively large supply effects. This shows that labor supply incentives of expansion of childcare services are also present in a country which has surpassed the EU target of childcare slots for $33 \%$ of children below the age of 3 (Belgium, in contrast with Germany and Italy). Moreover, budgetary simulations suggest the expansion to be beneficial to the exchequer. Rising tax and social security benefits following the increase in labor supply largely exceed the costs of expansion.

\section{Introduction}

Childcare is a key factor in the employment decisions of parents, especially of mothers. The availability of different childcare options, their quality and their price are major determinants of the work-family balance of households with (young) children. These issues figure also highly on the policy agenda, which is illustrated by the Europe 2020 target of increasing employment rates toward 2020 to $75 \%$ for the population aged between 20 and 64 . Especially for women there is scope to increase the employment rate, and formal childcare provisions figure prominently among the policy instruments to achieve this goal. ${ }^{1}$ The Barcelona childcare targets formulated in 2002 by the European Council, and confirmed in 2005 , should be viewed as part of this framework. ${ }^{2}$

In this paper we investigate the effect of different childcare options in terms of availability and prices on employment decisions of mothers with young children in Flanders (Belgium). The case of Flanders and/or Belgium in this domain remains largely under-studied, even though the childcare context is interesting from an internationally comparative viewpoint. To some extent, the Belgian welfare state remains oriented towards the breadwinner model (e.g. in the form of substantial derived social security rights, tax support for sole earners). However, in contrast to other continental welfare states, such as Germany, Belgium combines this with a well-organized and more wide-spread system of institutional childcare, and can thus be characterized by what Leitner (2005) called 'optional

1 According to EUROSTAT, the employment rate for men in the EU in 2010, the year when Europe 2020 was launched, was $75.1 \%$ while for women it was $62.1 \%$

2 According to these targets, each country should provide childcare by 2010 to at least $90 \%$ of children between 3 years old and the mandatory school age and at least 33\% of children under 3 years of age. 
familialism'. With an enrolment rate in formal care of children younger than three of $48.4 \%$ (2008), Belgium figures among the top nations in this respect in the OECD. ${ }^{3}$

Nevertheless, this does not mean that availability of childcare places is not an issue in Belgium. There are indications that all three forms of non-parental childcare that we distinguish (i.e. informal care, non-subsidized and subsidized formal care types) are characterized by excess demand, and hence that rationing is at work in the three types. The richness of our dataset, the Flemish Families and Care Survey, allows us to incorporate this triple rationing in our empirical analysis, which is a novelty in the literature. The distinction between types allows for a robust identification of price and availability (supply) effects, since the price and supply of the types varies strongly between municipalities, while the service quality is relatively homogeneous, because public supervision extends to all types of (formal) childcare.

Our paper builds on a structural labor supply model as proposed by Van Soest (1995), using a discrete random utility maximization model. We extend this framework by explicitly taking triple rationing in the Flemish childcare market into account. We do so in two ways. First, in line with Wrohlich (2011), access restrictions to childcare are taken into account in the budget constraint of each household. The expected price households pay for childcare depends on household-specific offer probabilities of each type of care. Households who enjoy a large probability of being offered a childcare spot of the informal type have a lower expected childcare cost than a similar household with a low offer probability of informal care. These offer probabilities are estimated by applying the partial observability framework, as suggested by Poirier (1980). In contrast to Wrohlich (2011), we also take rationing in the formal non-subsidized childcare sector into account, as we have clear evidence that this sector also faces excess demand. Second, in the estimation of the labor supply model we make a distinction between two different groups of households depending on their access to childcare. Households that have a low probability of finding suitable childcare in general are assumed to face a restricted labor supply choice set.

This paper contributes to the existing literature in several ways. First, because we have clear evidence that the non-subsidized childcare sector in Flanders faces excess demand, we extend the framework suggested by Wrohlich (2011) and explicitly take this rationing into account in the model. Thus, we no longer rely on an automatic market clearing assumption to identify rationing effects. Second, we propose an alternative way of taking total rationing in the childcare market into account in the estimation of the labor supply model by distinguishing between two groups of households, i.e. the non-restricted and restricted households. Households who face a low probability of finding suitable childcare, face a restricted labor supply choice set. Finally, our methodology can be used to analyse how labor supply is affected by different policy changes. In line with estimates from countries with stronger supply restrictions (Italy and Germany), we find that, for a country with a relatively generous service supply, maternal labor supply is more sensitive to changes in the availability of care than to changes in price. Not surprisingly, the estimates of the net budgetary effect of expansion plans are strongly positive.

The paper is organized as follows. Section 2 discusses the childcare context in Flanders. Section 2 gives a brief overview of related studies in the literature. Section 4 explains in detail how the

Only the Nordic States and the Netherlands have higher rates (OECD, 2011). 
different offer probabilities for the three types of childcare are estimated by applying the partial observability model suggested by Poirier (1980). Section 5 presents our methodological framework, and the data assumptions are explained in Section 6. The labor supply estimation results and labor supply impact of some alternative policy scenarios are presented in Section 7. The final section concludes.

\section{Childcare in Flanders}

This section discusses the childcare context in Belgium and more specifically in Flanders. Section 2.1 gives an overview of which categories of care can be distinguished and how frequently they are used. Section 2.2 discusses in further detail three important elements of the childcare market in Flanders: the price, the quality, and the availability of childcare.

\subsection{Types and usage of childcare}

The childcare landscape in Belgium, and more specifically in Flanders, is highly fragmented, as can be seen in Table (1), but can roughly be divided in two categories: formal and informal care. Child and Family (Kind en Gezin, K\&G) supervises the organization of formal childcare in Flanders and controls whether childcare providers meet the legal requirements. ${ }^{4}$ Formal childcare mainly focuses on children between 3 (end of maternity leave) and 30 months (start of publicly-financed nursery school).

A closer look at formal childcare providers suggests a distinction between subsidized and nonsubsidized care. The former receives cost-covering subsidies from Child and Family, for which they need to be accredited. The formal non-subsidized childcare providers are not eligible for these subsidies, and need only to register. ${ }^{5}$ In both cases, parents can apply for a tax deduction, which is not the case if providers do not register. Therefore, client pressure may explain why almost all formal care providers (both subsidized and nonsubsidized) are registered, and thus controlled by Child and Family. Secondly, in both subsidized and non-subsidized care, a distinction can be made between child-minders and day nurseries. Child-minders take care of a relatively small group (max. 8) of children in their own house, whereas day nurseries are located in specific childcare centres. There are also local services for neighbourhood-oriented care that are small childcare initiatives aimed at providing diverse and easily accessible childcare, especially for more vulnerable families. ${ }^{6}$ Child and Family partly subsidizes the latter initiatives working towards equal opportunities (Ghysels and Vercammen (2012) \& Kind en Gezin (2012)).

4 The same is undertaken by the Bureau of Birth and Childhood (Office de la Naissance et de l'Enfance, ONE) in the French speaking community.)

5 In order to be accredited, childcare facilities need to fulfill different legal requirements, which is not the case if you are only registered.

6 The first initiatives of local services for neighbourhood oriented care were taken in 1998 in Brussels, Antwerp and Leuven. They received project-based support from Child and Family. Since 2009, this type of childcare is legally and structurally integrated into the Flemish childcare landscape. More information can be found at: http://www.lokalediensteneconomie.be/node/9. 
Beside formal childcare, informal childcare is also an important care channel. Mainly grandparents, but also other family members, neighbours, or friends are possible providers of care.

User surveys reported in Bettens et al (2002) and Hedebouw and Peetermans (2009b), reveal a strong increase in the frequent use of childcare (from $49 \%$ in 2001 to $63 \%$ in 2009). ${ }^{7}$ The percentage of families that never used any type of childcare gradually decreased from $41 \%$ in 2001 to $31 \%$ in 2009. Table (1) looks at the evolution of the main childcare choices amongst families in Flanders. The use of informal care as the primary care-taking channel decreased in favor of formal care (mainly the non-subsidized part of it). Within the non-subsidized formal care sector, the most notable rise regards the (near) doubling of child minders as the primary care-taking channel between 2001 and 2009.

Table 1: Most frequently used type of childcare, 3 months -3 years, Flanders (\%).

\begin{tabular}{lcc}
\hline & $\mathbf{2 0 0 1}$ & $\mathbf{2 0 0 9}$ \\
\hline Formal subsidized care & $\mathbf{4 5 . 6}$ & $\mathbf{4 6 . 9}$ \\
- Child-minders & 28.7 & 28.5 \\
- Day nurseries & 16.9 & 18.4 \\
Formal non-subsidized care & $\mathbf{1 7 . 8}$ & $\mathbf{2 3 . 9}$ \\
- Child-minders & 9.6 & 17.6 \\
- Day nurseries & 8.2 & 6.3 \\
Informal care (grandparents) & $\mathbf{2 9 . 9}$ & $\mathbf{2 2 . 4}$ \\
\hline
\end{tabular}

Source: Bettens et al (2002) and Hedebouw and Peetermans (2009b)

\subsection{Price, quality and availability of childcare}

The price, quality and availability are three central factors of the market for childcare services. This section discusses each of these items in detail for the Flemish childcare context.

\subsubsection{The price of childcare in Flanders}

A first important aspect of childcare relates to the price paid by parents. This price differs according to the type and amount of care.

Subsidized providers of formal childcare are obliged to apply a legally determined means tested tariff structure, dependent on household income. The payment rate differs in blocks, rather than hourly proportions. ${ }^{8}$ In 2005, which is the year of the survey used in this paper, $78 \%$ of the children who

$7 \quad$ The category 'frequently' means minimum 5 hours of childcare per week. For preschool children, these 5 hours need to take place in a continuous period. For children between 2,5 and 3 years going to a nursery school, this continuity is not necessary.

8 Four different categories can be distinguished. A Mini Day amounts to [0,3[ hours of care/day and is charged $40 \%$ of the daily cost. A Half Day reflects [3,5[ hours/day and is charged $60 \%$ of the daily cost. A Whole Day is equal to the range of $[5,12$ [ hours/day and is charged at $100 \%$ of the daily price and a Maxi Day reflects $[12,24[$ hours/day and costs $160 \%$ of the daily cost. 
were in formal subsidized childcare stayed a whole day (between 5 and 12 hours) and paid $100 \%$ of the daily price. This daily price lies between a minimum price of 1.28 Euro and a maximum of 22.82 Euro with an average cost of 13.5 Euro. A discount of 2.58 Euro is given for each dependent child in the family, after the first, and for multiples. ${ }^{9}$ Childcare providers can also freely choose to apply a social tariff for households in a financially difficult situation, which is either 75,50 or $25 \%$ of the normal means-tested tariff. ${ }^{10}$

Non-subsidized providers of formal childcare are free to determine the price they charge. Not much information is available about the price setting by these providers. The best source available is a Child and Family report from 2009 (Hedebouw and Peetermans, 2009a). Based on this report, we can determine the average daily cost for a whole day in non-subsidized care for children between 0 and 3 years old in Flanders. On average, a non-subsidized child minder charges 17.16 Euro in 2009 and a non-subsidized day nursery 21.16 Euro. Reacting upon concern about the growing market share of the non-subsidized sector (see Table (1)), and hence the expected growing cost for low income families, the Flemish government introduced, as a test case, in 2009 the means-tested tariff system in the non-subsidized sector. Registered but non-subsidized facilities may opt to join the system wherein the same means-tested tariff structure as in the subsidized sector is applied. The Flemish government complements the parent's means-tested contribution up to a guaranteed daily price. ${ }^{11}$ (Ghysels and Vercammen (2012)).

Additionally, parents who use accredited childcare (both formal subsidized and nonsubsidized) are eligible for a tax deduction. The taxable income of the fiscal unit is reduced with out-of-pocket costs of childcare service, with a maximum of 11.20 Euro per day per child in care. Since 2005, this is possible for dependent children until the age of 12 . Families who do not deduct childcare fees qualify for a lump sum raise of the income tax exemption, equal to 520 Euro for every child younger than 3 in 2012 (Ghysels et al (2010)).

No information about prices (parental costs) in the informal sector is available. In the empirical part of this paper, we assume that the cost paid by the parents for informal childcare equals zero, which is the common assumption in the literature.

\subsubsection{The quality of Flemish childcare facilities}

A second important element is the quality of the care provided by the different child care facilities. Both formal subsidized and non-subsidized childcare meet the legal requirements of quality care, as determined by Child and Family. However, this doesn't guarantee a permanent level of high quality in itself. A quality check is only done at the opening of a care center or when deemed necessary (e.g. after several complaints). The caretaker is therefore itself responsible for the level of quality provided. Yet, this structural comment does not obviate that satisfaction among parents is very high.

9 For 2012, the minimum daily price is 1.5 Euro, the maximum price 26.68 Euro and the average daily cost is 13.7 Euro. A discount of 3.02 Euro is given for each dependent child in the family.

10 No information about the frequency of use of this social tariff is available.

11 Within the simulations presented in this paper, we use data from 2005. This means that we don't use the means-tested tariff structure for the non-subsidized childcare sector, because this was first implemented in 2009. 
A survey conducted by Child and Family in 2009 (Hedebouw and Peetermans (2009a)) gives an idea about the quality of childcare as perceived by parents in Flanders with a child between 0-3 years old. $96.2 \%$ judge the quality of the main care taking channel as very good (64.2\%) or good (32\%). Informal care (mainly grandparents) is perceived as the most qualitative form of care. Formal non-subsidized is considered the least qualitative one, although still more than $95 \%$ of the users judge this type of care as very good $(55.9 \%)$ or good (39.4\%). Questions about the well being of the child in childcare gave similar results.

\subsubsection{Triple rationing in the Flemish childcare market}

A final important element regards the availability of childcare. There are indications that all sorts of childcare services are in short supply in Flanders. Research commissioned by Child and Family in 2007 indicated that $10 \%$ of parents were not able to secure a suitable childcare service after a search period of six months (Market Analysis and Synthesis (2007)). Obviously, we acknowledge that a crosssection result based on those who are currently in the market does not provide full information on the dynamics of demand and supply. In effect, supply may expand in the medium term and excess demand may be eliminated by market forces. Haan and Wrohlich (2011) assume in their analysis of labor and childcare in Germany, for example, that market forces automatically clear the market through supply by non-subsidized providers. In their approach, rationing is limited to supply of subsidized and informal care, which does not respond to classic market dynamics (e.g. rising prices).

Figure 1: Recent evolution in coverage rate of childcare for children aged up to three, 2002-2009

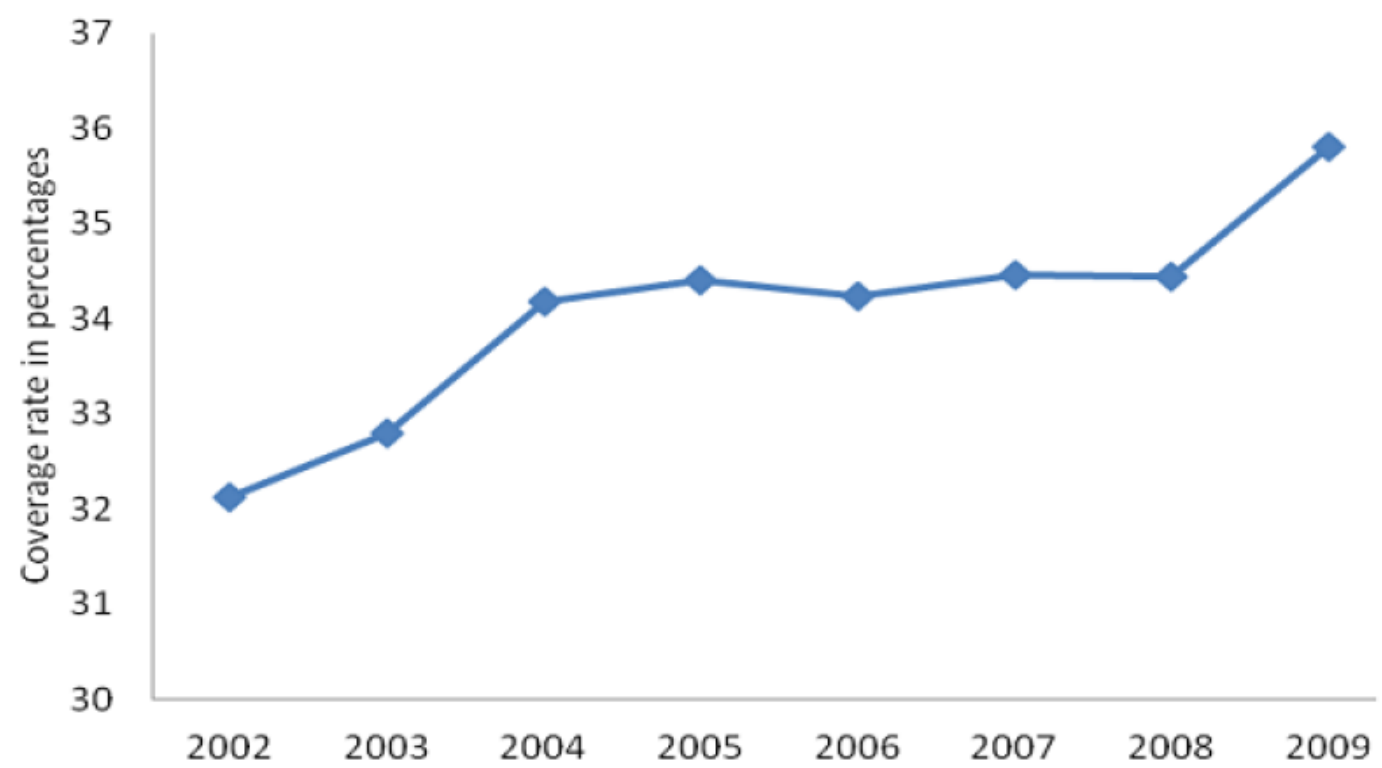

Source: Own calculation based on Kind and Gezin. (2002-2009). Jaarverslag Kinderopvang. Brussels. Note: coverage rates are measured in full-time equivalents (i.e. the number of childcare places in full-time equivalent divided by the total number of children in the age interval 0 to 3 )

However, the recent past of Flemish childcare supply does not signal a quick response of the formal childcare sector and, hence, questions the assumption of automatic market clearing. On the positive side, the evolution reflected in Figure 1 does show that total provision in the formal sector has grown. Yet, the growth rate hardly surpasses rises in the birth rate, and does not account for growing 
employment rates among mothers. Knowing concurrently that informal (grandparental) care is on the decline (Ghysels and Van Vlasselaer (2007)), it is clear that over the last decade overall excess demand (formal+informal) has not been eliminated.

Our second observation relates to the composition of the Flemish childcare services market, which suggests a three-levelled hierarchy of rationing. Rationing that most parents are likely to be confronted with, stems from the changing role of grandparents. As in most European countries (Hank and Buber(2009)), the care contribution of grandparents is decreasing in Flanders. Several explanations are given, such as more active ageing, through which grandparents are still working or do not have the time to take care of children. Meanwhile, many parents state that grandparents are their preferred care providers (Ghysels and Debacker (2007)), which should not come as a surprise given their traditional role in child-raising and the fact that they usually do not charge a price for their help.

Yet, childcare rationing goes beyond the informal part. Development of subsidized and nonsubsidized formal childcare led to locally uneven results. Municipal supply statistics corresponding to our period of analysis (December 2004) show that the coverage rate ${ }^{12}$ of subsidized childcare averaged $24 \%$ and the coverage rate of non-subsidized childcare averaged $11 \%{ }^{13}$ For formal childcare overall, Flanders, 340 municipalities had an average coverage rate of $34 \%$ (interquartile range 27 to $40 \%$ ). While one small municipality boasted a coverage rate of over $100 \%$, it is more important to observe that the 95th percentile's coverage rate is only $54 \%$. Confronted with municipal employment rates of mothers with young children of on average $70 \%$, there is little doubt that rationing in both the subsidized and the non-subsidized childcare sectors may exist in at least some locations. ${ }^{14}$ Therefore, we will assume that besides grandparental rationing, parents can also experience rationing in subsidized and non-subsidized formal childcare.

\section{Literature review}

There exists a large amount of literature describing the effect of children, and more specifically the effect of childcare, on parental labor supply. Anderson and Levine (1999), Brewer and Paull (2004) and Kalb (2009) provide overviews of the existing studies related to childcare and labor supply. This latter study discusses in detail how the cost, availability and quality of childcare affect parental labor supply decisions for different countries.

The literature about labor supply and childcare demand can be broadly classified into two categories depending on the assumptions made regarding parental demand for childcare. The first stream considers childcare as a way to make time available for parents to engage in market work. As such, childcare only forms part of the cost of working and the demand for care is completely determined

12 The coverage rate is defined as the amount of slots as a percentage of children below the age of 3 living in the municipality.

13 The interquartile range for the former equals $27 \%$ to $40 \%$ and for the latter $3 \%$ to $16 \%$.

14 Note that the part-time nature of demand for childcare does not warrant a simple equation of the coverage rate with the employment rate of mothers. In effect, a full-time childcare slot may cover for more than one child. As a rule of thumb, the Flemish childcare authority 'Kind en Gezin' assumes in its planning exercises that a full-time slot can cover the demand of 1.2 children. 
by the parental labor supply decision. This is known in the literature as the "Cost of Working" approach, and only the employment decision is endogenously modelled. Kimmel (1995), Averett et al (1997) and Wrohlich (2004) are examples of studies that can be found in this stream of literature. The second stream assumes that households make their employment and childcare decisions simultaneously, and thus it is known as the "Simultaneous" approach. Examples of studies that work in the "Simultaneous" approach are Connely (1992) and Ribar (1995) for the United States and Kornstad and Thoresen (2007) for Norway. ${ }^{15}$ The work presented in this paper can be situated in the first stream of literature as our main purpose is to see how employment decisions are affected by characteristics of the childcare market and not how childcare choices are made.

The existing literature focuses mainly on three aspects of childcare: price, quality and availability. Basic economic intuition suggests the price of childcare to be one of the most important features of childcare in the parental labor supply decision. Hence, many studies, regardless of working with a "Cost of Working" or "Simultaneous" approach, have put emphasis on these costs to explain labor market behaviour, such as the participation decision of mothers. These effects are most often presented as elasticities that report the percentage change of labor supply and labor market participation which results from a percentage change in childcare prices. Anderson and Levine (1999), Brewer and Paull (2004), Kalb (2009) and Gong, Breunig and King (2010) provide summary tables of estimated elasticities for different countries and subgroups. Their estimates vary across a wide range but indicate that, on average, childcare prices affect labor supply negatively. For example, Blau and Robins (1988) find for the United States an elasticity of maternal employment relative to the price of childcare of -0.34; Ribar (1995) reports an elasticity of - 0.09 for married women in the United States; and Wrohlich (2004) finds an elasticity of -0.21 for German mothers with full-time working husbands. Gong, Breunig and King (2010) state that this variation partly reflects the fact that childcare and other welfare institutions vary across countries and that differences in methodology and data sources may also play an important role, making a direct comparison difficult. Anderson and Levine (1999) find that papers taking a structural approach obtain elasticities on the lower end of these estimates, ranging between 0 and -0.1 .

In more recent literature, the focus has shifted from the cost of childcare to its availability and accessibility. This literature provides mixed evidence of the size and sign of the effect of these availability constraints on labor supply. For Germany, Hank and Kreyenfeld (2000) employ a multinomial logit model to estimate how the availability of public and informal day-care arrangements affect female labor-force participation. The authors find no significant effect of regional childcare provision on female labor-force participation. Wrohlich (2011), however, does find significant labor supply responses for German mothers of an increase in childcare availability. Wrohlich (2011) models availability restrictions explicitly in the budget constraint, and assumes that rationing occurs only with respect to subsidized childcare. The author assumes that childcare can always be bought at some (potentially very high) price on the private market. Wrohlich (2011) shows that policy reforms in Germany targeted at an increase in childcare slots had larger effects on maternal labor supply than reductions of the cost in childcare. For Italy, Del Boca (2002), Del Boca and Vuri (2007) and Brilli et al. (2011) find a positive impact of childcare availability on the likelihood of mothers working. These studies restrict the choice set of households according to a simulated probability of being rationed in the childcare sector. For Russia, Lokshin (2004) models rationing by

15 For a more detailed overview, see Brewer and Paull (2004) and Kalb (2009) 
restricting the choice set of parents who report to be rationed in the childcare market. Kornstad and Thoresen (2007) follow a similar method for Norway. Both studies find positive labor supply responses to increased availability of the childcare sector.

For Belgium in particular, there is hardly any literature about the effects of childcare on labor supply decision of households. The only recent paper that estimates labor supply elasticities with respect to childcare costs is Van Klaveren and Ghysels (2012). The authors find, in contrast to many studies in the literature, positive labor supply elasticities with respect to childcare costs. However, it is hard to compare their work to the work presented in this paper because the authors use a collective household model which treats childcare costs as a pure income effect, given the power balance (sharing rule) in the household. Rising costs reduce the non-labor income of the household and, hence, motivate parents to increase their working hours. Farfan-Portet, Lorant and Petrella (2011) analyse the impact of both demand-side and supply-side subsidies on the use of formal childcare by low income families in Belgium. They conclude that the choice of policy instruments is not neutral in terms of access to formal childcare for families of different income groups. As such, the authors call for a heterogenous treatment of rationing and availability restrictions, taking household characteristics into account. We will return to this issue below.

\section{Triple rationing in the childcare sector}

This section discusses in detail how rationing in the childcare sector is accounted for. Given the triple face of rationing, we look in detail at the search process of parents when looking for a suitable childcare place and estimate the probability of them being rationed in their childcare choice. ${ }^{16}$

\subsection{Rationing and the stepwise search for a childcare slot}

Earlier, we characterized the Flemish childcare market and described its three main types of care. In this section we develop an ordered estimation strategy based on the price and quality attributes of the three types of care, which suggests a rationing hierarchy. Grandparents hardly ever charge for their care, which makes their care by far the most cost attractive for parents. Even if opinions on the inherent quality of grandparents as carers may differ between parents, we assume the price element to trump potential preference issues and, hence, assume that parents who are looking for childcare will first turn to the grandparents if available. ${ }^{17}$ Only if they cannot assure grandparental care to cover their full care needs, parents will start searching within the formal sector.

Within the Flemish formal childcare sector, prices can be treated as the dominant factor. The regulatory framework ensures that all types of providers attain high quality levels, but prices vary strongly. ${ }^{18}$ In the subsidized sector, parents pay an income-related fee with a maximum of $€ 25$ per day, while non-subsidized providers are free to determine their prices. Even though a survey

16 Note that we do not make a distinction between rationing for childminders and day nurseries. We only focus on the distinction between informal, formal subsidized care and formal non-subsidized care.

17 Ghysels and Debacker (2007) show that grandparental care is the most preferred type of childcare. See also section 2.2

18 Non-accredited providers are believed to be of marginal importance. (Kind en Gezin 2010) 
amongst non-subsidized providers of childcare services in 2008 suggested that hardly any of them charge a daily price over the maximum of the subsidized tariff ${ }^{19}$, their prices are not income-related and, hence, using childcare in the non-subsidized sector results in considerably higher costs than in the subsidized sector for most parents. ${ }^{20}$ Therefore, we assume the non-subsidized sector to be the provider of last resort, when parents cannot cover their care needs with grandparental help nor with care from a subsidized care provider.

In short, we assume the search process of parents to follow the cost hierarchy of childcare services in Flanders: first grandparents are considered as childcare providers, then an offer of subsidized childcare is looked for and lastly parents attain whether they can secure a slot in the more expensive non-subsidized sector.

\subsection{Rationing estimation through partial observability models}

As will be discussed in the following section, our labor supply model incorporates estimates of the offer probabilities of childcare that parents experience. The model necessitates household-specific offer probabilities of childcare in general and for each type of care individually. The general offer probability will be used to determine the set of labor market choices that are open to specific parents, while the offer probabilities of each type will be combined into a household-specific price of childcare.

Therefore, we estimate four offer probabilities: total supply (any type of childcare), supply in the subsidized sector, supply in the non-subsidized sector and supply of informal care (grandparental care).

To estimate these supply probabilities, we rely on a simultaneous estimate of demand and supply of childcare using the partial observability probit framework suggested by Poirier (1980) and adapted to a childcare setting by Viitanen and Chevalier (2003). We do not apply the modified framework suggested by Wrohlich (2008), because, unlike Germany, we see no large group of municipalities with full coverage, as already documented above. The historically high supply of childcare services in the eastern part of Germany allowed Wrohlich (2008) to restrict estimation to demand for only part of her sample, but no such situation exists in Flanders. ${ }^{21}$

Following Poirier (1980), we treat the observed use of a childcare service of household $i, C_{i}$, as the combined result of two unobserved, binary elements: having been offered a slot (effective supply $S_{i}^{*}$ ) and having decided to use the offer (effective demand $D_{i}^{*}$ ). ${ }^{22}$ With all variables in the following equation to take values $\{0,1\}$, it is easily seen that use can only be observed when both supply and demand are secured (i.e. equal to 1 ).

19 Unpublished data obtained from the Flemish governing authority 'Kind en Gezin'.

20 Earlier calculations by the authors indicate that even in the ninth income decile the income-related fee amounts to less than 20 Euros a day, a $20 \%$ discount with regard to the usual price in the formal sector (childcare centres).

21 Neither do we rely on panel data, which might allow us to treat parents who had a slot in the year before to be non-rationed as in Haan and Wrohlich (2011).

22 For a detailed discussion of the methodology of partial observability models, we refer to the Appendix. 


$$
C_{i}=S_{i}^{*} \cdot D_{i}^{*}
$$

Poirier (1980) suggests modelling the realization of the two defining elements of observed use as separate equations in a bivariate probit model. For our subsequent labor supply estimates, we will only use point estimates of the supply part. In effect, the likelihood of an offer of the childcare type concerned is exactly the (complement of the) family-specific rationing probability that we need in the labor supply equation.

To obtain identified estimates, Poirier (1980) proved - unsurprisingly - that exclusive instruments are needed in every equation (supply and demand). For the estimation of the overall use of childcare services (all types together), we identify demand through determinants of maternal market work (maternal health, father's labor market status, property status of the family dwelling, maternal mother's working status during the childhood of the mother and maternal task division preferences). Supply is identified through various indicators of grandparental availability and the coverage rate of formal childcare services for the municipality of the household.

Regarding grandparental care, we identify supply through variables that have proven to determine grandparental childcare efforts in earlier research (Uhlenberg and Hammill 1998; Hank and Buber 2009): the health of grandparents, their employment status and the distance between their home and the home of the children requiring care. Demand by the parents is identified through a preference indicator in the dataset, which relates to the preferred type of childcare of the father (a similar indicator for the mother is not included to avoid multicollinearity with other characteristics of the mother).

Regarding subsidized care, we assume the likelihood of an effective offer to be identified by the municipal structure of childcare supply (coverage rate and proportion of subsidized provision). Furthermore, indicators of the search skills of the parents (educational level of the mother and poverty status) are included, as the latter proved to be linked to the rationing experience in the 2007 research of MAS (Market Analysis and Synthesis 2007), and various elements that determine the preference rules of subsidised childcare institutions (family composition, family income), are taken into account. The latter allows us to clarify that in our framework supply is to be understood as the offer as experienced (perceived) by the household. To the extent that household characteristics explain variation in the offer experienced by the household (because of search skills and/or preference rules), these characteristics are determinants of supply. We identify demand through the inclusion of preference indicators regarding formal childcare, and the likelihood of grandparental care as estimated in the grandparent procedure. The latter follows from our hierarchical understanding of the search process (see Section 4.1). We expect parents with a high likelihood of grandparental support to be less inclined to look for formal childcare.

Regarding non-subsidized care, we rely for identification of supply on the municipal structure of formal childcare. For demand, we incorporate preference indicators regarding formal childcare and include the previously estimated likelihoods of grandparental care and subsidized care. Again, the latter reflects the assumed hierarchy in the childcare search process, which sees the most expensive type of care (non-subsidized care) as less likely to be demanded when either grandparental care or subsidized care are expected (i.e. have high estimated use probabilities). 
Finally, since the rationing indicators are to be used in subsequent labor supply estimates, we do not incorporate the employment status of the mother in itself as a control variable. However, we do include the age and education level of the mother and incorporate furthermore the age of the youngest child and the number of children in the household as common determinants of supply and demand. While not being exclusive instruments, they do influence the eventual use of childcare services.

Descriptive information on the variables included is given in Table (20) in the appendix. The reader may note that the stated preferences regarding the type of childcare service reflects a high proportion of formal-, rather than informal -care to be the first choice of 13 mothers and fathers. Yet, we should not obviate that preference questions are likely to be biased, since parents are invited to reflect on abstract preferences and not to take costs and rationing into consideration. Therefore, we hereafter model the choice process as a combination of supply and demand considerations.

Empirically, we estimate the likelihood of childcare utilization for the youngest child in the household, excluding children younger than 6 months, because maternity and parental leave regulations largely depress demand for childcare services for younger children. ${ }^{23}$ We assume that parents with more than one child between the ages of 7 and 35 months use similar arrangements for all these children. Above the age of 35 months, the use of childcare services is drastically reduced, because children quasi-universally enter pre-primary education before the age of three.

\subsection{Estimates}

Table 2 shows the results of the four estimation procedures described above. ${ }^{24}$ It reflects the predicted offer probabilities of informal or grandparental care, formal subsidized, formal nonsubsidized care $\left(p_{i}^{i n f}, p_{i}^{f s}, p_{i}^{f n s}\right)$ and the predicted probability of an offer of any type of childcare service $p_{i}^{t o t}$, which is the combined probability of parents finding grandparents willing to take care of their child and/or finding a formal childcare slot of any type. The table shows that the latter probability, $p_{i}^{\text {tot }}$, is not a simple sum of the underlying probabilities $\left(p_{i}^{\text {inf }}, p_{i}^{f s}, p_{i}^{f n s}\right)$. This follows from the importance of combination probabilities as shown in the following equation:

$$
\begin{aligned}
p_{i}^{\text {tot }}= & p_{i}^{\text {inf }}+p_{i}^{f s}+p_{i}^{f n s}- \\
& p\left(S_{i}^{\text {inf }} \cup S_{i}^{f s}\right)-p\left(S_{i}^{f s} \cup S_{i}^{f n s}\right)-p\left(S_{i}^{\text {inf }} \cup S_{i}^{f n s}\right)+ \\
& p\left(S_{i}^{\text {inf }} \cup S_{i}^{f s} \cup S_{i}^{f n s}\right),
\end{aligned}
$$

with $\mathrm{S}$ denoting supply and $\mathrm{p}$ referring to a (supply) probability.

In the empirical procedure, we have avoided estimating every combination probability separately, by estimating the total offer probability directly. Table 2 shows that parents face an average supply probability of .82 , with $7 \%(1-93 \%)$ of the parents in our sample living in a situation of excess demand, i.e. being totally rationed in childcare.

\footnotetext{
23 Haan and Wrohlich (2011) avoid estimations for all children younger than 12 months, but our dataset shows that in Flanders childcare service use resumes earlier than in Germany.

${ }^{24}$ The estimated coefficients are included in the appendix.
} 
The variation in the predicted offer probabilities of the separate types of care, on the other hand, underpins the distinction we will make when calculating the expected cost of childcare. As will be discussed further in Section 5.2.2, due to the high variation in offer probabilities for the three different sectors, we expect the price of childcare to vary strongly between households.

Table 2: Predicted offer probabilities of three types of childcare services

\begin{tabular}{lcrrr}
\hline Type of care & Mean pred. probability & p25 & p75 & \% above .50 \\
\hline (1) Grandparental care $p_{i}^{\text {inf }}$ & .50 & .30 & .72 & $50 \%$ \\
(2) Subsidized formal care $p_{i}^{\text {fs }}$ & .86 & .81 & .99 & $90 \%$ \\
(3) Non-subsidized formal care $p_{i}^{\text {fns }}$ & .63 & .33 & .95 & $64 \%$ \\
(4) Any type of childcare service $p_{i}^{\text {tot }}$ & .82 & .73 & .95 & $93 \%$ \\
\hline
\end{tabular}

Source: Own Calculations, FFCS (2005), N = 51215

\section{Theoretical framework}

The first part of this section provides a brief overview of the existing methodology of labor supply modelling and the second discusses the model applied in this paper.

\subsection{Modelling labor supply}

Up to the nineties, labor supply was modelled in a continuous way, see Hausman and Ruud (1984) and Arrufat and Zabalza (1986), where the household chooses from a continuous set of hours. The household selects the best combination of labor supply and consumption so as to maximize its utility function, given a time and budget constraint. However, this way of modelling labor supply was increasingly criticized. First, assuming a continuous set of hours implies that one has to derive the full budget constraint of each household, i.e. the net disposable income, at each hour-point. This often leads to practical problems and time-consuming work. Second, the maximization problem is very complex because the tax function is often non-linear, which leads to non-convex budget sets. Third, the model does not allow for individual utility maximisation, but rather assumes homogeneous household decision making. Finally, and possibly the most important drawback of this methodology, the assumption that individuals may choose their optimal point anywhere along the budget constraint is not realistic. As pointed out by Aaberge and Colombino (1999), the structure of labor costs makes it less attractive to firms to offer contracts that allow for flexible work schedules. Consequently, the choice set available for the individual may be severely reduced.

In order to overcome several of these problems, researchers have made use of a discrete random utility maximization model (RUM) initiated by Daniel McFadden (1974). ${ }^{25}$ Two distinct features can be observed when comparing this method with the continuous approach. In this methodology the household's hour-choices can be approximated by a discretized set instead of a continuous one. Secondly, the optimal labor supply choice is modelled in terms of a comparison of the different utility

25 McFadden (1974) applied these random utility models to several transport and occupational choices. He considered these choices to be discrete. 
levels at the discrete choices. Introducing a random utility term that is assumed to be distributed according to an extreme value distribution leads to an easy expression for the probability that any particular discrete labor supply point is chosen. These models are structural in the sense that there is no reduced form labor supply function which depends on wages and non-labor income but that the structural parameters for the preference for consumption and leisure are identified out of an a priori assumed functional form of the utility function. Van Soest (1995) can be seen as one of the first papers that applied this random utility framework to the estimation of labor supply. Our paper estimates such a discrete labor supply model for Flanders, with an explicit focus on childcare.

\subsection{Methodological framework}

This subsection explains in detail which labor supply model is estimated, and how we extend the model suggested by Van Soest (1995) by taking childcare explicitly into account. We develop our approach only for couple households with a father engaged in full-time work. In other words, the choice variable of the household is the labor supply of the mother. labor income of the father is assumed to be given. We will discuss the exact empirical relevance of this selection of households below.

\subsubsection{General outline of the model}

Van Soest (1995) assumes that each household is confronted with a limited amount of labor supply alternatives $j=\{0,1, \ldots, J\}$. The utility of household $i$ when supplying $j=\{0,1, \ldots, J)$ hours of work per week is equal to:

$$
V_{i, j}=U_{i}\left(\left(T-h_{i, j}\right), C_{i, j} \mid X_{i}\right)+\epsilon_{i, j}
$$

in which $T$ stands for the total available time per week, $h_{i, j}$ represents total labor supply of mother $i$ at alternative $j, X_{i}$ are household characteristics and $C_{i, j}$ stands for total disposable household income when the mother works $j$ hours per week. In line with Van Soest (1995), we assume that utility $V_{i j} j$ can be divided in two parts. The first element of equation 3 reflects the structural or deterministic component of utility which is assumed to be known to both researcher and household. This deterministic part depends on the amount of weekly non-working time, $\left(T-h_{i j}\right)$ and total disposable household income $C_{i, j}$ at the chosen discrete point $j$, given household characteristics $X_{i}$. The second part is random and is unknown to the researcher but assumed to be known to each household individually. This term arises from factors such as measurement errors concerning the variables in $X_{i}$, optimization errors of the individual, or the existence of unobserved preference characteristics.

Assuming that the random term is identically and independently distributed across households and alternatives according to an extreme value distribution, McFadden (1974) shows that the probability that household $i$ chooses an alternative $k$ from their choice set $j=\{0,1, \ldots, J\}$ is given by

$$
\begin{aligned}
p_{i, k} & =\operatorname{Pr}\left(V_{i, k} \geq V_{i, j}, \forall j=0, \ldots J\right) \\
& =\frac{\exp U_{i}\left(\left(T-h_{i, k}\right), C_{i, k} \mid X_{i}\right)}{\sum_{j=0}^{J} \exp U_{i}\left(\left(T-h_{i, j}\right), C_{i, j} \mid X_{i}\right)}
\end{aligned}
$$


Van Soest (1995) assumes that each discrete labor supply point from the choice set $j=$ $\{0,1, \ldots, J\}$ is equally available and accessible to each household. ${ }^{26}$ Above, we argued that some households face availability restrictions in the childcare market and do not find suitable childcare if needed. Therefore, we extend the standard Van Soest (1995) model and assume that mothers who are rationed in their childcare choice have a restricted labor supply choice set $j=\{0\}$ that includes only non-participation. Mothers who have a probability of being offered a childcare spot in general $p_{i}^{t o t}$ that is lower than $50 \%$, are assumed to be restricted in their choice set and do not have the opportunity to accept market work. According to Table (2), $7 \%$ of all households in our sample face a restricted choice set.

The parameters of the utility function $U_{i}$ are estimated by maximum likelihood as the individual likelihood contributions, and can be derived from expression (4). Households that face a restricted choice set are not taken into account in the estimation of the household preferences as their individual log likelihood contribution is zero.

\subsubsection{Specification of the model}

According to Equation (3), the deterministic part of household utility depends on the amount of nonworking time of the mother $\left(T-h_{i, j}\right)$ and net disposable household income $C_{i, j}$ when working $j$ hours. In line with Keane and Moffit (1998) and Blundell et al. (1999), we assume the following quadratic specification for the deterministic part of utility:

$$
\begin{aligned}
U_{i}\left(\left(T-h_{i, j}\right), C_{i, j} \mid X_{i}\right)= & \beta_{c}\left[C_{i, j}\right]+\beta_{c c}\left[C_{i, j}\right]^{2}+ \\
& \beta_{h}\left(X_{i}\right)\left[T-h_{i, j}\right]+\beta_{h h}\left[T-h_{i, j}\right]^{2}+ \\
& \beta_{h c}\left[T-h_{i, j}\right] \cdot\left[C_{i, j}\right]
\end{aligned}
$$

where we allowed for interaction effects between non-working time and income. We allow for heterogeneity in the estimated coefficient for non-working time $(T-h)$ :

$$
\beta_{h}\left(X_{i}\right)=\beta_{h, 0}+\beta_{h}^{\prime} X_{i}^{h}
$$

where $X_{i}^{h}$ is a vector representing the observed heterogeneity that contains variables such as education and age of the mother, and number and age of children.

The net disposable household income $C_{i, j}$ of household $i$ when supplying $j$ amount of hours can be formally written as:

$$
C_{i, j}=t\left(h_{i, j} \cdot w_{i}, I_{i}\right)-\mathrm{E}\left[P_{i, j}\right],
$$

\footnotetext{
26 Note, however, that Van Soest (1995) includes alternative specific constants for part-time work in the estimation of the model in order to account for the lack of availability of part-time jobs.
} 
where the function $t$ denotes the tax-transfer system, wi stands for the hourly gross wage, li represents all non-labor income ${ }^{27}$ and $E\left[P_{i, j}\right]$ equals the expected childcare costs for household $i$ when working $j$ hours.

When mothers are considering labor supply, we assume they take into account two decision elements regarding childcare: the probability of finding a slot of any type, which determines the possibility to accept a job offer, and the price they are expected to pay for the service, which influences the net gain of a potential job offer. The former is included in our model in the restricted choice set of some households and the latter is reflected in the budget constraint of each household. The expected price of childcare of household $i$ with the mother working $j$ hours per week is the weighted average of the unit price of the three different types of childcare for $j$ hours of care per week: ${ }^{28}$

$$
\mathrm{E}\left[P_{i, j}\right]=z_{i}^{i n f} \cdot P_{i, j}^{i n f}+z_{i}^{f s} \cdot P_{i, j}^{f s}+z_{i}^{f n s} \cdot P_{i, j}^{f n s} .
$$

The household-specific weights for the informal childcare market and the formal subsidized and formal non-subsidized childcare markets are represented respectively by $z_{i}^{\text {inf }}, z_{i}^{f s}$ and $z_{i}^{\text {fns }}$. The household-specific price for the three different childcare types when working $\mathrm{j}$ hours is given by $P_{i, j}^{i n f}, P_{i, j}^{f s}$ and $P_{i, j}^{f n s}$. Given the zero price of grandparental care, the former equation reduces to:

$$
\mathrm{E}\left[P_{i, j}\right]=z_{i}^{f s} \cdot P_{i, j}^{f s}+z_{i}^{f n s} \cdot P_{i, j}^{f n s}
$$

In this equation, weights depend on the likelihood of an offer of a particular type of care relative to the other likelihoods, see Section 4.3. The reference value is not straightforward, however. A simple approximation of parental behaviour assumes that parents sum all likelihoods and assign weights proportionally, as in:

$$
z_{i}^{t}=\frac{p_{i}^{t}}{p_{i}^{\text {inf }}+p_{i}^{f s}+p_{i}^{f n s}}, \text { for } t=\{f s, f n s\}
$$

Yet this assumes that parents do not discriminate between price options, while rationality assumes that decision makers choose, ceteris paribus, the least costly solution. Hence, in their demand for childcare parents can be assumed to choose grandparental care over formal childcare options, because the former is free and the latter are not, and to choose for subsidized formal childcare over non-subsidized childcare, because the former is generally cheaper than the latter. The denominator of the following weighting equation takes this stepwise demand pattern into account, assuming that the probability of formal care is only counted to the extent informal care is not expected to be available, $\left(1-p^{\text {inf }}\right)$, and the probability of non-subsidized care is weighted to an even lesser degree

27 The model is estimated for married mothers with a full-time working husband. The income of this spouse is an element of mothers' non-labor income.

28 As discussed before, we assume that the demand for childcare equals the amount of labor supply. 
because it is the option of last resort, and depends on the probabilities of the two preceding options, $\left(1-p^{\text {inf }}\right)\left(1-p^{f s}\right)$. Therefore, the weights used in Equation 9 are given by: ${ }^{29}$

$$
\begin{gathered}
z_{i}^{f s}=\frac{\left(1-p_{i}^{i n f}\right) \cdot p_{i}^{f s}}{\left[p_{i}^{f s}+\left(1-p_{i}^{f s}\right) \cdot p_{i}^{f n s}\right]} \\
z_{i}^{f n s}=\frac{\left(1-p_{i}^{i n f}\right) \cdot\left(1-p_{i}^{f s}\right) \cdot p_{i}^{f n s}}{\left[p_{i}^{f s}+\left(1-p_{i}^{f s}\right) \cdot p_{i}^{f n s}\right]}
\end{gathered}
$$

\section{Data assumptions and childcare rationing}

Section 6.1 provides an overview of the data which is used in this study. Section 6.2 briefly shows which discrete labor supply points are available for each household. Finally, we discuss in detail how the budget constraints look and how they are affected by childcare costs.

\subsection{Data}

This paper uses data from the 2004-2005 Flemish Families and Care Survey (FFCS) that contains a representative sample of 1275 Flemish families with a youngest child aged up to three years. ${ }^{30}$ The survey contains relevant information such as childcare utilization, the cost of childcare, household income, working hours and household characteristics. ${ }^{31}$

The model presented in this paper is estimated on a subsample of couples. ${ }^{32}$ Only couples in which both partners are available for the labor market are retained in our sample. Moreover, we only consider the labor supply decision of the mother, and focus on couples in which the father works fulltime. ${ }^{33}$ We try to keep the model relatively simple by focusing on this specific subgroup which represents the most common situation among families with young children. ${ }^{34}$ Hence, we can investigate the labor supply decisions of mothers separately.

Both partners need to be aged between 18 and 65 years old and not in education, (pre)retired, disabled or ill. Self-employed individuals are excluded from the sample for two reasons: no reliable information about hours worked is available for them, and the labor supply decisions of self-

29 Note that Equations 11 and 12 contain a normalizing factor $\left(1-p^{\text {inf }}\right)$, which ensures that the sum of the weights for the formal care options to be $\left(1-p^{\text {inf }}\right)$ and hence to complement the weight of informal care which carries a zero price.

30 We do not use data from the Survey of Income and Living Conditions (SILC) for our analysis, which is the standard database used in Flemosi-based simulations. The reason for this is twofold: first, we are unable to distinguish in SILC between formal subsidized and formal non-subsidized childcare. The second, and most important reason is that the SILC data does not contain enough Flemish families with a youngest child between 0 and 3 years old.

31 For more information about the FFCS, see Debacker et al. (2006).

32 Not enough cases of single mothers (58 cases) or single fathers (10 cases) are available in our sub-sample to estimate a separate discrete labor supply model.

33 Full-time work is equal to the interval $[35,60]$ hours per week.

34 In $76 \%$ of households with a child below 3 years old, the father was working full-time in 2005 (Ghysels and Debacker, 2007:26). 
employed people are possibly very different from those of salaried workers. Furthermore, households with children already available for the labor market but still living with their parents are excluded from the sample. The reason for this is that it is possible that their labor supply decisions are different from households without working children, because it is not clear whether the former households see their labor supply decision as a collective or an individual process. We retain a dataset containing 512 households. Descriptive statistics about this sub-sample can be found in Table (21) in appendix.

Figure 2: Hours distribution female

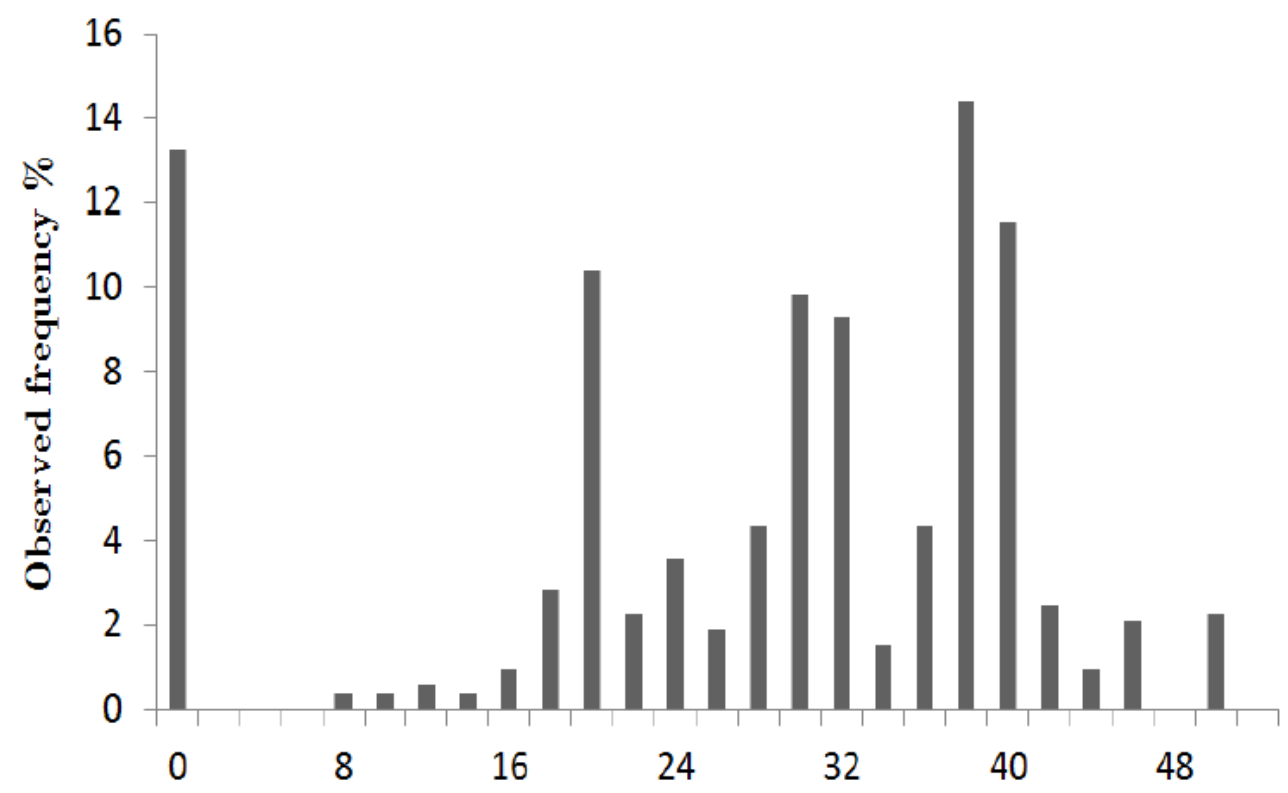

\subsection{Discrete labor supply points}

In the Flemish Family and Care Survey (FFCS), information on the number of weekly hours worked in the month before the interview was given, and is presented in Figure (2). We assume that women face a choice set of four discrete points; not working ( 0 hours), working part-time ( 20 hours), $80 \%$ work (32 hours) and working full-time (40 hours). ${ }^{35}$

As already discussed in Section 3, we use a cost of working approach, which considers childcare only as a way to make time available for mothers to engage in market work. This means that the amount of care is completely determined by the maternal labor supply. Households in which the mother is not working do not require childcare. If the mother works part-time, households demand 2 full days and 1 half day of care. A mother who works 4 days in a week is in need of 4 full days of childcare and a full-time working mother needs 5 days of childcare. ${ }^{36}$ We make the assumption that it is not possible for parents to work and take care of their children at the same time. Also, the assumption is

35 Not working equals the interval $[0,10]$ hours/week, part-time is equal to $[11,25]$ hours/week, $4 / 5$ to $[26,35]$ hours/week and full-time reflects the interval $[35,50]$ hours/week.

36 A half day of childcare is charged $60 \%$ of a full day. Hence, 2 full days and 1 half day is charged 2,6 full days. 
made that parents are unable to organize their working hours in a flexible way, in order to be able to maximize the amount of time they can take care of their children themselves.

\subsection{Budget constraints}

In order to be able to estimate the model presented in Section 5, household disposable net income is required for each discrete point (see Equation 7). We apply the tax benefit microsimulation model Euromod for the derivation of these budget constraints. ${ }^{37}$

Gross earnings from employment are calculated by multiplying gross hourly wages by the respective working hour in each hours category. We hereby make the assumption that the hourly wage rate is independent of the amount of hours worked, which implies that gross earnings increase linearly with working time. Due to this assumption, hourly wages, are obtained by dividing observed gross income by the actual observed number of hours worked.

There are also households where gross earnings are not observed, for example households with unemployed or inactive mothers. Most studies in the literature apply a Heckman correction model for the estimation of hourly wages in order to avoid biased estimations due to sample selection. It could be that the average wage for someone in the labor market is substantially different than for someone who is out of work. Participants in the labor market may have observable and/or unobservable characteristics that determine wages and that are different from the ones of the inactive or unemployed. We estimated such a Heckman correction model for women, but found that the selection effect was not significant. ${ }^{38}$ Consequently, there is no need to account for a possible selection effect and a simple wage regression can be used. The estimation results of this wage regression can be found in Table (22) in appendix. As expected, higher experience and higher schooling lead to higher gross hourly wages. ${ }^{39}$

Gross household income is equal to the sum of the labor earnings of all household members. The income tax and employees' social security contributions are deducted from gross income, and social transfers are added to obtain the net disposable household income. Social transfers include child benefits, education benefits for students and housing benefits. No social assistance benefits or unemployment benefits are granted to households. ${ }^{40}$

According to Equation 7, expected childcare costs are also taken into account in the calculation of the budget constraint. Given the estimated probabilities of receiving an offer of childcare for the three sectors (see Table (2)) and the stepwise search for care by parents, we derive the expected childcare cost for each household at each discrete labor supply point according to Equation 9. The higher the probability of being offered a place in informal care, the lower the expected childcare cost. The lower the probability of an informal childcare place, the higher the expected childcare cost, as households

\footnotetext{
37 More information about Euromod can be found at https://www.iser.essex.ac.uk/euromod.

38 Results are available from the authors upon request.

39 Wages are imputed for 76 households (14,8\% of our sample).

40 We only look at households in which the male works full-time, so these families are not eligible for meanstested social assistance.
} 
must rely on more expensive childcare such as formal subsidized or non-subsidized care. ${ }^{41}$ These expected costs are included in Euromod and then subtracted from households' net disposable income. For the calculation of the cost of formal subsidized childcare, we simulate the 2005 tariff structure in detail. We use a Child and Family survey of 2009 for the calculation of the cost of formal non-subsidized childcare (Hedebouw and Peetermans, 2009b). As mentioned before, we can only determine the average daily cost of care by a child-minder (17.16 Euro) or by a day nursery (21.16 Euro), respectively $68 \%$ and $84 \%$ of the maximum daily cost in the subsidized sector in 2009 . We used these percentages to calculate an average daily cost of childcare by a non-subsidized child minder and a non-subsidized day nursery in 2005. This resulted in a daily cost of 15.23 Euro for a child minder and 18.8 Euro for a day nursery, respectively $68 \%$ and $84 \%$ of the maximum daily cost in the subsidized sector in 2005 . In line with the formal subsidized sector, we charge only $60 \%$ of the daily price for half a day of childcare in the formal non-subsidized sector. For both the subsidized and non-subsidized sector, the tax deduction for childcare is simulated within Euromod. Childcare in the informal care sector is assumed to be free of charge.

Table 3 presents the cost of childcare for an average household in our sample for each of the three types of childcare. By assumption, the price households have to pay for informal care in each of the four discrete labor supply points is zero. If, on the other hand, this average household uses formal subsidized care it would pay 126 Euro/month when the mother is working 20 hours per week. This amount increases to 295 Euro/month when working full-time. A similar household that uses formal non-subsidized childcare pays a considerably higher fee for each of the three strictly positive labor supply points.

Table 3: Illustration of average cost of childcare (Euro/month)

\begin{tabular}{lccc}
\hline & Informal childcare & Formal sub. care & Formal non-sub. care \\
\hline 0 hours & 0 & 0 & 0 \\
20 hours & 0 & 126 & 170 \\
32 hours & 0 & 221 & 262 \\
40 hours & 0 & 295 & 327 \\
\hline
\end{tabular}

Source: Own Calculations, FFCS (2005)

Table 4 provides summary statistics of the weighting factors in the childcare cost equation 8 . On average, the cost of formal subsidized care is for $45.90 \%$ accounted for and the average weight for formal non-subsidized childcare equals only $3.68 \%$. The weight for informal care, which is provided for free, is on average $50.41 \%$. We see, however, a large variation in these weights by looking at the

41 An example can make this more clear. Take a low income family whereby the female, if working, has a gross hourly wage of 8 Euro. The male works 40 hours and has a gross hourly wage of 12 Euro. They have one child younger than 3 years old. In a first simulation, we assume that the expected probability of receiving an offer for this family equals in the informal childcare sector $80 \%$, and in both the formal subsidized and non-subsidized sector $30 \%$. The expected cost of childcare for this family is calculated using Euromod and equals 25 Euro / month, 41 Euro / month or 54 Euro / month, when the female works respectively $20,32 \& 40$ hours per week. In a second simulation, we assume an expected probability of $30 \%$ in both the informal and the formal subsidized childcare sectors, and of $80 \%$ in the more expensive formal subsidized sector. The expected cost of childcare for this family equals now 100, 160 and 205 Euro per month, when the female works respectively $20,32 \& 40$ hours per week. 
minimum and maximum. Consequently, the expected price of childcare varies strongly between different types of households.

Table 4: $\quad$ Childcare cost weighting factor

\begin{tabular}{lcccc}
\hline & Mean & Std. dev & Min & Max \\
\hline Informal $z_{i}^{\text {inf }}$ & 50.41 & 26.28 & 1.24 & 99.17 \\
Formal sub $z_{i}^{\text {fs }}$ & 45.90 & 27.89 & 0.10 & 98.75 \\
Formal non-sub $z_{i}^{\text {fns }}$ & 3.68 & 8.14 & 0.00 & 63.82 \\
\hline
\end{tabular}

Source: Own Calculations, FFCS (2005)

Table 5 provides summary statistics of the budget constraints. The average household income if the mother is not participating in the labor market equals 2579 Euro/month. Remember that we focus solely on households in which the father is working full-time. This income is included in the budget constraint, and explains why net disposable income when working 0 hours is considerable. The more the mother works, the higher the average net disposable household income.

Table 5: $\quad$ Net disposable household income (Euro/month)

\begin{tabular}{lcccc}
\hline & Mean & Std. dev & Min & Max \\
\hline 0 hours & 2579 & 700 & 1004 & 6482 \\
20 hours & 3275 & 753 & 1671 & 7120 \\
32 hours & 3649 & 804 & 1951 & 7491 \\
40 hours & 3879 & 843 & 2115 & 7788 \\
\hline
\end{tabular}

Source: Own Calculations, FFCS (2005)

\section{Labor supply estimation results}

This section discusses the results from the labor supply estimation by looking at the parameter estimates of the quadratic utility specification. In order to fully capture the heterogeneity in preference structure, we present an overview of the marginal rate of substitution for different subgroups, look at the fit of the model, and calculate labor supply elasticities. Section 7.2 looks at the effect of childcare costs on maternal labor supply in Flanders, and discusses how rationing affects maternal labor supply decisions.

\subsection{Labor supply estimates}

Table (6) presents the estimated parameters of the quadratic utility function in Equation 5. Looking at the estimated coefficients for non-working time, we clearly see that there exists heterogeneity in preferences for leisure. The parameter for age of the mother has a significant negative value and the quadratic term is significantly positive. Older mothers appear to attribute less value to non-working time than younger women. We find that the taste for non-working time increases with the presence of children, the size of the coefficient depending on the age of the children. The estimated coefficients with respect to schooling reveal that mothers without higher education have a larger 
preference for leisure than highly educated mothers. Consumption positively affects a mother's utility and the quadratic term for consumption is negative, which is in line with the theoretical predictions. Note that no heterogeneity is included for preference for consumption.

Table 6: Estimated parameters of quadratic utility function

\begin{tabular}{lcccc}
\hline & Coeff. & Std. error & 95\% conf. int. \\
\hline Consumption $\left(\beta_{c}\right)$ & & & & \\
Consumption sq. $\left(\beta_{c c}\right)$ & $8.504^{* *}$ & 3.120 & 2.389 & 14.618 \\
& $-0.621^{* *}$ & 0.268 & -1.150 & -0.096 \\
Non-work time $\left(\beta_{f}\left(X_{i}\right)\right)$ & & & & \\
Age & & & & \\
Age squared & $-0.027^{* *}$ & 0.011 & -0.049 & -0.005 \\
Children 0-3 & $0.0004^{* *}$ & 0.0001 & 0.000 & 0.001 \\
Children 4-6 & $0.021^{* *}$ & 0.009 & 0.003 & 0.039 \\
Children 7-9 & $0.033^{* *}$ & 0.008 & 0.017 & 0.047 \\
Higher education & $0.027^{* *}$ & 0.0101 & 0.006 & 0.047 \\
Constant & $-0.026^{* *}$ & 0.001 & -0.045 & -0.007 \\
& $0.595^{* *}$ & 0.216 & 0.171 & 1.0718 \\
Non-work time sq. $\left(\beta_{f f}.\right)$ & & & & \\
Non-work time * Cons. $\left(\beta_{f c}\right)$ & $-0.028^{*}$ & 0.019 & -0.065 & 0.007 \\
\hline
\end{tabular}

*Significant at $10 \%$ level, ** Significant at $5 \%$ level

Source: Own Calculations, FFCS (2005)

A comparison of the actually observed and predicted frequencies of mothers in each discrete labor supply point shows that the estimated model fits the data very well, see Table (7).

Table 7: $\quad$ Observed and predicted labor supply densities

\begin{tabular}{lcc}
\hline & Observed density & Estimated density \\
\hline 0 hours & 19.36 & 18.50 \\
20 hours & 20.70 & 19.93 \\
32 hours & 26.56 & 27.76 \\
40 hours & 34.38 & 33.80 \\
\hline
\end{tabular}

Source: Own Calculations, FFCS (2005)

Table (8) presents the preference heterogeneity by means of the variation in the marginal rates of substitution for different subgroups. For each observation in our sample, we calculate the slope of the indifference curve at the same bundle of 20 hours work and a net disposable monthly income of 3200 Euro, which is the average income observed for 20 hours of work per week. Different marginal rates of substitution reveal different preferences for the considered subgroups. An average mother in the whole sub-sample requests a compensation of 17.3 Euro for one additional hour of work. We see that a mother without a university degree has a higher preference for leisure than a similar mother with a university degree. The former is willing to give up 23.4 Euro for one additional hour of non-working time, whereas the latter is only willing to sacrifice 14.1 Euro. The amount of preschool children also clearly affects mother's preferences. A mother with only one child between 0 and 3 
years old has a marginal rate of substitution of 17.0 Euro. A similar mother with two preschool children has a marginal rate of substitution of 18.0, and this increases to 33.0 Euro for a mother with three preschool children. Having more preschool children leads to higher preferences for nonworking time.

Table 8: Marginal rates of substitution

\begin{tabular}{lcc}
\hline Subgroup & Marginal rate of substitution & Standard error \\
\hline Whole sample & 17.3 & 10.5 \\
& & \\
No university degree & 23.4 & 10.2 \\
University degree & 14.1 & 9.1 \\
& & \\
One child 0-3 & 17.0 & 10.7 \\
Two children 0-3 & 18.0 & 9.5 \\
Three children 0-3 & 33.0 & 9.9 \\
\hline
\end{tabular}

Note: Marginal rates of substitution were calculated in the bundle $(C, h)=(3200,20)$

Source: Own Calculations, FFCS (2005)

An alternative way of interpreting the estimated coefficients is by looking at the size of labor supply responses with respect to changes in budgetary constraints. Table (9) provides the elasticities with respect to a increases in gross hourly wages and childcare prices. The structural basis of a discrete labor supply model implies that there is no explicit labor supply function from where one can derive the wage elasticity. Therefore, numerical methods are used to analyse the sensitivity of labor supply with respect to wage changes. The individual's gross wage or childcare cost is increased by $10 \%$, keeping all the other characteristics constant. We simulate the new budget constraint of each household using Euromod, and the new expected labor supply can be calculated, given the estimated coefficients. The hours elasticity expresses the percentage change in total hours supplied with respect to a given percentage increase in gross hourly wage or childcare cost. The participation elasticity is defined as the expected percentage change in labor market participation after a given percentage change in gross wages or childcare cost.

We find a total hours elasticity for wages of 0.275 and a participation elasticity of 0.192 . These results are in line with expectations and the literature, see, for example, Blundell and MaCurdy (1999) and Keane and Rogerson (2012). For Belgium more specifically, Orsini (2006) estimates total hours elasticity in the range $[0.16,0.30]$ and participation elasticity between $[0.10,0.19]{ }^{42}$

The participation elasticity with respect to childcare costs is equal to -0.034 and total hours elasticity to -0.056 . In line with the literature, these labor supply elasticities are negative and rather small. Increasing the cost of childcare by 10 percent leads to a small decrease in labor force participation of $3.4 \%$ for the subgroup of Flemish mothers. Flemish maternal labor supply appears to be rather

42 Orsini (2006) estimated a similar quadratic utility function on the Panel Survey of Belgian Households for 2001 on the whole subgroup of married women and not specifically on married women with preschool children and full-time working fathers. 
insensitive to price changes. ${ }^{43}$ Wrohlich (2011) asserts that policy reforms related to the rationing in the childcare market are more effective than reforms that focus on the cost of care. Section 7.2 investigates if this statement also holds for Flanders.

Table 9: $\quad$ Labor supply elasticities

\begin{tabular}{lcc}
\hline & Participation elast. & Total hours elast. \\
\hline Wage increase & 0.192 & 0.275 \\
Childcare cost increase & -0.034 & -0.056 \\
\hline
\end{tabular}

Source: Own Calculations, FFCS (2005)

\subsection{Labor supply impact of alternative policy measures}

The model can be used to analyse how policy proposals potentially affect Flemish maternal labor supply. We present the results of four different policy proposals by looking at the labor force participation rate and the percentage change in total hours.

The first two simulations are related to the calculation of the labor supply elasticities from Section 7.1. A $10 \%$ increase in gross hourly wages leads to an increase in total labor supply of $2.75 \%$, and the labor force participation rate changes from $81.50 \%$ up to $83.11 \%$. Increasing the cost of childcare by $10 \%$ only leads to a decrease of $0.56 \%$ in labor supply and to a change of 0.30 percentage points in the labor force participation rate.

The third and fourth simulations are examples of two extreme reforms that are hardly implementable but are useful for gaining important insight of potential labor supply responses. The policy debate on childcare reforms often boils down to the discussion of whether to decrease the cost of care or to increase the availability and accessibility of childcare facilities. According to Table (10), providing free childcare given the current availability constraints in childcare supply would lead to an increase of $3.49 \%$ in total labor supply. The maternal labor force participation rate would increase with 1.74 percentage point from $81.50 \%$ up to $83.24 \%{ }^{44}$

The fourth simulation assumes that there are no availability constraints in the formal subsidized childcare sector. Consequently, the expected childcare costs are lower for almost all households due to the fact that formal non-subsidized care is more expensive. Additionally, and most importantly, the elimination of rationing results in the fact that some households are no longer constrained in their labor supply choice. In the baseline situation, some households do not have the option of working due to the lack of suitable childcare. These restricted households have a probability of being offered childcare in general that is lower than $50 \%$. Due to this counter-factual simulation, these households can now choose their labor supply from the complete choice set. Total labor supply

43 Van Klaveren and Ghysels (2012) draw the same conclusion for Flemish households. However, they find small positive labor supply elasticities with respect to the cost of childcare.

44 We assume that the supply of childcare is flexible enough to cover this limited increase in demand. However, we cannot completely rule out that this reform also necessitates a slight increase in childcare capacity. 
increases by $6.34 \%$ and the labor force participation rate of Flemish mothers in our sub-sample increases to $87.29 \%$ instead of $81.50 \%$.

Table (11) presents the governmental cost of implementing these two simulations. The provision of free childcare would cost the Flemish government 7.2 million Euro per month (in 2005 prices). ${ }^{45}$ By far the biggest cost is the parental contribution, which is now assumed to be paid by the government. However, this simulation leads to additional employment which results in extra revenues for the government. Making childcare free leads to an increase in governmental revenue of 5.2 million per month. Taking these additional revenues into account, the compensatory effect for the government of this measure is $72.7 \%$ of the initial budgetary cost. If, on the other hand, the government would provide enough suitable childcare, the compensatory effect is much larger and equals $474.8 \%$. Eliminating the excess demand for childcare leads to a governmental cost of 1.0 million Euro/month for subsidizing new childcare places. Due to the large employment effects, the extra revenue equals 4.8 million Euro/month. The cost per new full-time equivalent worker in the third simulation equals 2766 Euro, whereas this cost is negative for the fourth simulation and equals -2883 Euro/FTE.

Table 10: Simulation results $L F P(\%)$

\begin{tabular}{lcc}
\hline & LFP(\%) & Change total hours(\%) \\
\hline Baseline & 81.50 & $/$ \\
10\% higher gross wage & 83.11 & +2.75 \\
10\% higher childcare costs & 81.20 & -0.56 \\
Free childcare & 83.24 & +3.49 \\
No rationing in childcare & 87.29 & +6.34 \\
\hline
\end{tabular}

Source: Own Calculations, FFCS (2005)

45 It is important to keep in mind that the model is estimated on a sub-sample, i.e. married mothers with fulltime working father and youngest child under 3 years old. Only the budgetary effects of this subgroup is taken into account in Table (11). 
Table 11: Budgetary cost (Euro/month)

\begin{tabular}{|c|c|c|}
\hline & Free childcare & No rationing in childcare \\
\hline Governmental cost: & 7225157 & 1007571 \\
\hline Subsidizing extra places & 502770 & 1007571 \\
\hline Cost of childcare: & 6722387 & / \\
\hline Governmental revenue: & 5254374 & 4783641 \\
\hline Change in SSC employer & 1013339 & 1733059 \\
\hline Change in SSC employee & 544499 & 1002054 \\
\hline Change in taxes & 3588141 & 1896093 \\
\hline Change in benefits & 108395 & 152435 \\
\hline Net governmental cost & 1970783 & $\begin{array}{lll}-3 & 776 & 070\end{array}$ \\
\hline Compensatory effect & $72.7 \%$ & $474.8 \%$ \\
\hline Cost per new FTE & 2766 & -2883 \\
\hline
\end{tabular}

SSC refers to Social Security Contributions;

Source: Own Calculations, FFCS (2005)

\section{Conclusion}

In this paper we have estimated the impact of childcare provisions on employment decisions of mothers with young children in Flanders. Even though parents state that grandparents are their preferred care providers, the care contribution of grandparents is decreasing in Flanders, in line with the trend in most European countries. Moreover, the coverage rate of subsidized and non-subsidized care in many Flemish municipalities does not suffice to avail all currently employed mothers. Hence, we conclude that not only is informal formal childcare characterized by rationing, but that we also have excess demand for non-subsidized and subsidized formal childcare options.

We integrate this triple rationing in our model in the form of a three-level hierarchy of rationing. By adopting the partial observability model of Poirier (1980), we estimate the rationing probabilities in all three childcare sectors and include these estimates in the budget constraint of each household. Subsequently, we estimate a discrete labor supply model of the Van Soest (1995) type, while allowing for heterogeneity in prices and distinguishing between rationed and non-rationed households.

The resulting labor supply elasticities have the expected sign: we find a small negative effect of childcare costs on both participation and hours-of-work decisions. This indicates that Flemish mothers with young children are hardly sensitive to price changes of childcare. The simulations we elaborated in the last section show that rather the availability of formal childcare slots is the bottleneck for mothers to increase their labor supply: when removing rationing in the subsidized formal childcare sector, the employment rate among our group of mothers would increase by 7.63 percentage points. 
Both the small impact of prices and the large supply effect are in line with previous findings for Germany and Italy, countries with a lower employment rate of mothers and less formal childcare use (below the Barcelona target of the EU) than is the case in Belgium, which surpassed the Barcelona target of childcare slots for $33 \%$ of children younger than three years, by 2005. Our analyses suggest that even beyond the Barcelona target there remains scope for expansion.

Moreover, the removal of rationing that we simulate shows some sizeable, positive budgetary effects for the government: the additional cost of increasing subsidized formal childcare would, in balance, result in extra government revenue mainly in the form of additional social contribution and tax receipts, with the revenue largely exceeding the extra costs. Even if we want to stress that the outcomes of our simulations should be interpreted as indications rather than as exact predictions, our results suggest an immediate and large benefit for the public budget.

\section{References}

Aaberge, R., U. Colombino, and S. Ström (1999), 'Labour Supply in Italy: An Empirical Analysis of Joint Household Decisions, with Taxes and Quantity Constraints', Journal of Applied Econometrics, $14(4), 403-422$.

Anderson, P. M., and P. B. Levine (1999), Child Care and Mothers' Employment Decisions. NBER Working Paper Series, 7058.

Arrufat, J. L., and A. Zabalza (1986), 'Female Labor Supply with Taxation, Random Preferences, and Optimization Errors', Econometrica, 54, 47-63.

Averett, S. L., H. E. Peters, and D. M. Waldman (1997), 'Tax Credits, Labor Supply, And Child Care', The Review of Economics and Statistics, 79(1), 125-135.

Bargain, O., and K. Orsini (2006), 'In-work policies in Europe: Killing two birds with one stone?', Labour Economics, 13, 667-697.

Bettens, C., B. Buysse, and K. Govaert (2002), Enquête inzake het gebruik van Kinderopvang voor kinderen jonger dan drie jaar.

Blau, D. M., and P. K. Robins (1988), 'Child-Care Costs and Family Labor Supply', The Review of Economics and Statistics, 70(3), 374-81.

Blundell, R., and T. Macurdy (1999), 'Labor supply: A review of alternative approaches', Handbook of Labor Economics, 3, 1559-1695.

Boca, D. D. (2002), 'The effect of child care and part time opportunities on participation and fertility decisions in Italy', Journal of Population Economics, 15(3), 549-573.

Boca, D. D., and D. Vuri (2007), 'The mismatch between employment and child care in Italy: the impact of rationing', Journal of Population Economics, 20(4), 805-832.

Brewer, M., and G. Paull (2004), Families and Children Strategic Analysis Programme (FACSAP) Reviewing approaches to understanding the link between childcare use and mothers' employment. DWP working paper No. 14.

Brilli, Y., D. Del Boca, and C. Pronzato (2011), Exploring the Impacts of Public Childcare on Mothers and Children in Italy: Does Rationing Play a Role?, IZA Discussion Papers 5918, Institute for the Study of Labor (IZA). 
Connelly, R. (1992), 'The Effect of Child Care Costs on Married Women's Labor Force Participation', The Review of Economics and Statistics, 74(1), 83-90.

Debacker, M., J. Ghysels, and E. Van Vlasselaer (2006), Gezinnen, Zorg en opvang in Vlaanderen (GEZO), Technical report CSB. Antwerp: Herman Deleeck Centre for Social Policy.

Farfan-Portet, M.-I., V. Lorant, and F. Petrella (2011), 'Access to Childcare Services: The Role of Demand and Supply-Side Policies', Population Research and Policy Review, 30(2), 165-183.

Ghysels, J., and M. Debacker (2007), Zorgen voor kinderen in Vlaanderen: een dagelijkse evenwichtsoefening?, Leuven: Acco.

Ghysels, J., J. Vanhille, and G. Verbist (2010), Taxing care: enhancing the value of childcare time in the dual earner era. CSB Working paper No. 10/01. Antwerp: Herman Deleeck Centre for Social Policy.

Ghysels, J., and K. Vercammen (2012), The beneficiaries of childcare expansion. CSB Working paper No. 12/02. Antwerp: Herman Deleeck Centre for Social Policy.

Ghysels, J., and E. V. Vlasselaer (2008), 'Child Well-being in Flanders: A Multidimensional Account', Social Indicators Research, 89(2), 283-304.

Haan, P., and K. Wrohlich (2011), 'Can child care policy encourage employment and fertility?: Evidence from a structural model', Labour Economics, 18(4), 498-512.

Hank, K., and I. Buber (2009), 'Grandparents caring for their grandchildren: findings from the 2004 Survey on Health, Ageing and Retirement in Europe', Journal of Family Issues, 30(1), 53-73.

Hausman, J. A., and P. Ruud (1986), 'Family Labor Supply With Taxes', American Economic Review, $74,242-248$.

Hedebouw, G., and A. Peetermans (2009a), Het gebruik van opvang voor kinderen jonger dan 3 jaar in het Vlaams Gewest. Leuven: Steunpunt Welzijn, Volksgezondheid en Gezin, p. 239.

Hedebouw, G. and A. Peetermans (2009b), Onderzoek naar het gebruik van opvang voor kinderen jonger dan 3 jaar in het Vlaamse Gewest in 2009. Samenvatting van de Resultaten. HIVA en Steunpunt Welzijn, Volksgezondheid en Gezin en met de medewerking van Kind en Gezin.

Kalb, G. (2009), 'Children, Labour Supply and Child Care: Challenges for Empirical Analysis', Australian Economic Review, 42(3), 276-299.

Keane, M., and R. Moffitt (1998), 'A structural model of multiple welfare program participation and labour supply', International Economic Review.

Keane, M., and R. Rogerson (2012), 'Micro and Macro Labor Supply Elasticities: A Reassessment of Conventional Wisdom', Journal of Economic Literature, 50(2), 464-76.

Kimmel, J. (1995), 'The Effectiveness of Child-Care Subsidies in Encouraging the Welfare to- Work Transition of Low-Income Single Mothers', American Economic Review, 85(2), 271-75.

Kind en Gezin (2002-2010), Jaarverslagen Kind en Gezin.

Kornstad, T., and T. O. Thoresen (2007), 'A Discrete Choice Model for Labor Supply and Child Care', Journal of Population Economics, 20(4), 781-803.

Kreyenfeld, M., and K. Hank (2000), 'Does the availability of child care influence the employment of mothers? Findings from western Germany', Population Research and Policy Review, 19, 317337, 10.1023/A:1026556309080. 
Leitner, S. (2005), 'Conservative familialism reconsidered: The case of Belgium', Acta Politica, 40, 419-439.

Lokshin, M. (2004), 'Household Childcare Choices and Womens Work Behavior in Russia', Journal of Human Resources, 39.

MAS (2007), 'Analyse van het zoekproces van ouders naar een voorschoolse kinderopvangplaats.', Leuven, MAS/Kind en Gezin.

MCFadden, D. (1974), 'Conditional logit analysis of qualitative choice behavior', Frontiers in Econometrics, Chapter 4.

Poirier, D. J. (1980), 'Partial observability in bivariate probit models', Journal of Econometrics, 12(2), 209-217.

Ribar, D. C. (1995), 'A Structural Model of Child Care and the Labor Supply of Married Women', Journal of Labor Economics, 13(3), 558-597.

Van Klaveren, C., and J. Ghysels (2012), 'Collective Labor Supply and Child Care Expenditures: Theory and Application', Journal of Labor Research, 33, 196-224, 10.1007/s12122-011-9127-4.

Van Soest, A. (1995), 'Structural Models of Family Labor Supply: A Discrete Choice Approach', The Journal of Human Resources, 30(1), 63-88.

Viitanen, T. K., and A. Chevalier (2003), The Supply of Childcare in Britain: Do Mothers Queue for Childcare?, Royal Economic Society Annual Conference 2003 211, Royal Economic Society.

Wrohlich, K. (2004), Child Care Costs and Mothers' Labor Supply: An Empirical Analysis for Germany, Discussion Papers of DIW Berlin 412, DIW Berlin, German Institute for Economic Research.

Wrohlich, K. (2008), 'The excess demand for subsidized child care in Germany', Applied Economics, 40(10), 1217-1228.

Wrohlich, K. (2011), Labor Supply and Child Care Choices in a Rationed Child Care Market, Discussion Papers of DIW Berlin 1169, DIW Berlin, German Institute for Economic Research. 


\section{Appendix}

\section{Partial observability model}

This section is based on Poirier (1980) and Ghysels and Vercammen (2012), and discusses in detail how partial observability models work, as suggested by Poirier (1980). The first subsection explains the model theoretically, and the second gives an overview of the estimation results of the partial observability model used in this paper.

\section{Methodology}

The partial observability methodology allows estimating the demand and supply for all three types of childcare, even if only the joint outcome $C_{i}$ (i.e. the current use of childcare of household $i$ ) can be observed. $C_{i}$ equals 1 if we observe that childcare is taken by household $i, 0$ or otherwise. This childcare status, whether a child uses informal or formal (subsidized and non-subsidized), is the only observable variable, as the effective demand and supply of childcare slots cannot be observed. The magnitude of rationing in each of the three childcare sectors (i.e. excess demand) becomes computable when we separately predict the probability that a child is offered a childcare spot and the probability that there is a demand for childcare.

The partial observability model can be stated as follows. ${ }^{46}$ We assume that demand for any type of childcare by household $i$ can be expressed by the latent variable $D_{i}^{*}$ which depends on child and household characteristics $X_{i, D}$ and a stochastic element $\epsilon_{i, D}$ :

$$
D_{i}^{*}=\beta_{D} X_{i, D}+\epsilon_{i, D}
$$

where $\beta_{D}$ is the vector of coefficients. We assume that households effectively demand childcare, expressed in the variable $D_{i}$ if $D_{i}^{*}$ is larger than zero:

$$
D_{i}=1 \text { if } D_{i}^{*}>0 \text {. }
$$

.Therefore, the probability that parents demand childcare is given by:

$$
\operatorname{Pr}\left[D_{i}=1\right]=\operatorname{Pr}\left[\epsilon_{i, D}>-\beta_{D} X_{i, D}\right] .
$$

In line with the modelling of demand of care, we assume that the supply of any type of childcare to household $i$ can be expressed by the latent variable $S_{i}^{*}$ which depends on a vector of child, household and regional characteristics $X_{i, S}$ and a random term $\epsilon_{i, S}$ :

$$
S_{i}^{*}=X_{i, S} \beta_{S}+\epsilon_{i, S}
$$

where $\beta_{S}$ reflects the vector of coefficients. Similar to observed demand, we assume that effective supply of a childcare slot to household $i$ is observed is $S_{i}^{*}$ is larger than zero:

$$
S_{i}=1 \text { if } S_{i}^{*}>0 \text {. }
$$

\footnotetext{
46 The following expressions are written in general terms but hold for all types of childcare.
} 
Consequently, the probability of being offered a childcare spot is given by:

$$
\operatorname{Pr}\left[S_{i}=1\right]=\operatorname{Pr}\left[\epsilon_{i, S}>-\beta_{S} X_{i, S}\right] \text {. }
$$

In the data we only observe information on whether a household $i$ uses care $\left(C_{i}=1\right)$ or does not $\left(C_{i}=\right.$ $0)$. However, this can be expressed as the joint outcome of both latent variables demand $D_{i}^{*}$ and supply $S_{i}^{*}$. The probability that someone is observed to use childcare is given by the joint probability that this person demands care and the probability that they are offered a childcare spot. In line with Poirier (1980), we assume that the random terms of demand (Equation 13) and supply (Equation 16) are standard normally distributed and cross-correlated through correlation parameter $\rho$ as in a bivariate probit model. The probability of observation can be written as follows:

$$
\operatorname{Pr}\left[C_{i}=1\right]=\operatorname{Pr}\left[S_{i}=1 \wedge D_{i}=1\right]
$$

Given Equations (13) to (18), the probability that we observe childcare usage can be written as follows:

$$
\operatorname{Pr}\left[C_{i}=1\right]=\Phi\left(\beta_{D} X_{i, D}, \beta_{S} X_{i, S}, \rho\right)
$$

where $\Phi$ denotes the bivariate standard normal distribution and $\rho$ refers to the correlation between the random terms of the underlying demand and supply functions.

In addition, the probability that no childcare use is observed can also be written as a joint outcome of demand and supply:

$$
\begin{aligned}
\operatorname{Pr}\left[C_{i}=0\right] & =1-\operatorname{Pr}\left[C_{i}=1\right] \\
& =\left[1-\Phi\left(\beta_{D} X_{i, D}, \beta_{S} X_{i, S}, \rho\right)\right] .
\end{aligned}
$$

Given Equations 20 and 21, the likelihood function $L$ is equal to:

$$
L\left(\beta_{D}, \beta_{S}, \rho\right)=\Sigma_{i=1}^{n} C_{i} \ln \left[\Phi\left(\beta_{D} X_{i, D}, \beta_{S} X_{i, S}, \rho\right)\right]+\left(1-C_{i}\right) \ln \left[1-\Phi\left(\beta_{D} X_{i, D}, \beta_{S} X_{i, S}, \rho\right)\right]
$$

Once the coefficients of the covariates of the likelihood function are estimated, the probabilities of being offered a spot in each childcare type can be derived. These estimates are used in the labor supply model for the estimation of the model and the derivation of the budget constraints.

\section{Estimation results}

In the following tables we provide the results of the intermediary estimation of the demand and supply of childcare services in total and the three types of childcare services separately through four partial observability probit procedures. We refer to the text for a discussion of the identifying variables that are specific to each equation. Table (12) highlights the results of the bivariate regression of demand for and access to (i.e. supply of) grandparental care. ${ }^{47}$ Table (14) presents the estimation results for demand and supply in the formal subsidized childcare sector, and Table (16)

47 Note that demand and supply are estimated simultaneously but due to limits of space, we provide the results in two separate tables. 
shows the estimation results for the non-subsidized childcare market. The final tables reflect the estimates of the procedure for total childcare service demand and supply.

Table 12: Bivariate regression of grandparental care

\begin{tabular}{lccc}
\hline Demand for care by grandparents & Coef. & Std. Err. \\
\hline Age of the youngest child (in months) & -0.322 & $* *$ & 0.103 \\
Age & 0.008 & $* *$ & 0.002 \\
Number of children & 0.298 & 0.307 \\
Age of mother & -0.023 & & 0.041 \\
Child with special needs (parental assessment)(0/1) & 0.154 & & 0.944 \\
Marital status (reference = married couple) & & & \\
2. Single parent & 2.632 & $* *$ & 1.235 \\
3. Non-maritally cohabiting & -0.011 & & 0.395 \\
Maternal grandmother's involvement in paid labor & & & \\
during childhood of mother & & & \\
2. During part of childhood & 0.638 & & 0.572 \\
3. Not at all & 0.840 & $* *$ & 0.405 \\
Mother's educational level (reference $=$ up to primary & & & \\
school) & & & \\
3. Secondary school education & -0.891 & & 0.906 \\
4. Higher education & -2.139 & $* *$ & 0.892 \\
Mother's preference regarding task division with & & & \\
partner (reference = male breadwinner family) & & & \\
2. Mother with less time-demanding job than father & -0.515 & & 0.564 \\
3. Partners with equally demanding jobs & -0.444 & & 0.559 \\
4. Other & -0.628 & & 0.635 \\
Mother in fair health (self-assessed)(0/1) & -0.189 & & 0.352 \\
Father's first preference regarding care is & 1.781 & $* *$ & 0.428 \\
grandparent (0/1) & & & \\
Father's economic status (reference = father not & & & \\
present) & & & \\
1. Full-time job & 0.168 & & 0.498 \\
2. Part-time job & 0.514 & & 0.623 \\
Constant & 4.167 & $* *$ & 1.877 \\
\hline
\end{tabular}

The following page contains the second part of the estimates 
Table 13: Bivariate regression of grandparental care (continued)

\begin{tabular}{lccc}
\hline Supply of grandparental care & Coef. & & Std. Err. \\
\hline Belongs to previous table & & & \\
Age of the youngest child in months & 0.162 & $* *$ & 0.078 \\
Age & -0.004 & $* *$ & 0.002 \\
Number of children in the household & -0.335 & $*$ & 0.187 \\
Mother's age (years) & -0.024 & & 0.029 \\
Child with special needs (parental assessment) (0/1) & 0.365 & & 0.685 \\
Marital status (reference = married couple) & & & \\
2. Single parent & -1.261 & $* *$ & 0.524 \\
3. Non-maritally cohabiting & -0.147 & & 0.320 \\
Maternal grandmother's involvement in paid labor & & & \\
during childhood of mother (reference $=$ over full & & & \\
period) & & & \\
2. During part of childhood & -0.570 & & 0.411 \\
3. Not at all & -0.975 & $* *$ & 0.278 \\
Mother's educational level (reference $=$ up to primary) & & & \\
3. Secondary school education & 0.139 & & 0.338 \\
4. Higher education & 1.045 & $* *$ & 0.412 \\
Type of municipality (reference $=$ residential) & & & \\
2. Rural community & -0.079 & & 0.220 \\
3. Economically concentrated or tourist & -0.175 & & 0.230 \\
4. Semi-urban & -0.496 & $* *$ & 0.233 \\
5. Urban & -0.399 & $* *$ & 0.200 \\
Childcare coverage in municipality (FTE/1000 0-2-year & 0.669 & & 0.688 \\
olds) & & & \\
Number of grandparents & -0.056 & & 0.075 \\
Grandparental availability index (health. working & 0.242 & $* *$ & 0.075 \\
status. living distance from family home) & & & \\
Constant & -0.714 & & 1.170 \\
\hline
\end{tabular}

$\mathrm{N}=869$. selection: families with child(ren) below 3 of FFCS (2004-2005)

Likelihood-ratio test of $\mathrm{rho}=0 \mathrm{chi}^{2}(1)=0.514$; use correctly predicted: $86 \%$

Significance values $*>90 \%$. ${ }^{* *}>95 \%$. Log-likelihood $=-285.549$ 
Table 14: Bivariate regression of subsidized formal childcare

\begin{tabular}{lrrr}
\hline Demand for care by subsidized formal care & Coef. & Std. Err. \\
\hline Age of the youngest child in months & 0.200 & $* *$ & 0.042 \\
Age & -0.005 & $* *$ & 0.001 \\
Number of children & -0.156 & $* *$ & 0.068 \\
Age of mother (years) & -0.008 & & 0.012 \\
Child with special needs (parental assessment)(0/1) & -0.444 & & 0.357 \\
Marital status (reference = married couple) & & & \\
2. Single parent & 0.418 & & 0.354 \\
3. Non-maritally cohabiting & -0.025 & & 0.136 \\
Maternal grandmother's involvement in paid labor & & & \\
during childhood of mother (reference = during full & & & \\
period) & & & \\
2. During part of childhood & -0.482 & $* *$ & 0.168 \\
3. Not at all & -0.472 & $* *$ & 0.169 \\
Mother's educational level (reference $=$ up tot primary) & & & \\
3. Secondary school education & 0.282 & & 0.196 \\
4. Higher education & 0.858 & $* *$ & 0.240 \\
Household income is below the poverty line (0/1) & 0.043 & & 0.280 \\
Owner of own house (0/1) & 0.291 & & 0.181 \\
Taxable value of the house (euros) & 0.000 & & 0.000 \\
Mother's preference of task division with partner & & & \\
(reference category: male breadwinner family) & & & \\
2. Mother with less time demanding job than father & 0.589 & $* *$ & 0.188 \\
3. Partners with equally demanding jobs & 0.482 & $* *$ & 0.190 \\
4. Other & 0.389 & & 0.251 \\
Mother in reasonable health (self assessed)(0/1) & 0.000 & & 0.188 \\
Formal care is father's first choice (0/1) & 1.062 & $* *$ & 0.107 \\
Predicted supply of grandparental childcare & -0.941 & $* *$ & 0.429 \\
Father's employment (reference = father not present) & & & \\
1. Full-time & 0.092 & & 0.260 \\
2. Part-time & -0.520 & & 0.401 \\
Constant & -2.319 & $* *$ & 0.609 \\
\hline
\end{tabular}

The following page contains the second part of the estimates 
Table 15: Bivariate regression of subsidized formal childcare (continued)

\begin{tabular}{lrrr}
\hline Supply for care by subsidized formal care & Coef. & & Std. Err. \\
\hline Belongs to previous table & & & \\
Age of the youngest child in months & -0.688 & $* *$ & 0.219 \\
Age & 0.016 & $* *$ & 0.005 \\
Number of children & 0.575 & $* *$ & 0.221 \\
Age of mother (years) & 0.156 & $* *$ & 0.042 \\
Child with special needs (parental assessment) (0/1) & -0.993 & $*$ & 0.571 \\
Marital status (reference = married couple) & & & \\
2. Single parent & 4.181 & $* *$ & 1.059 \\
3. Non-maritally cohabiting & 0.900 & $* *$ & 0.457 \\
Mother's educational level (reference $=$ up to primary) & & & \\
3. Secondary school education & 0.337 & & 0.634 \\
4. Higher education & 0.053 & & 0.634 \\
Household income is below the poverty line (0/1) & -2.670 & $* *$ & 0.647 \\
Type of municipality (reference $=$ residential) & & & \\
2. Rural community & -0.523 & & 0.382 \\
3. Economically concentrated or tourist & -1.388 & $* *$ & 0.368 \\
4. Semi-urban & 1.611 & $*$ & 0.961 \\
5. Urban & 0.838 & & 0.563 \\
Childcare coverage in municipality (FTE/1000 0-2 year & -1.893 & & 1.303 \\
olds) & & & \\
Proportion of formal care is non-subsidized & -3.436 & $* *$ & 1.182 \\
center-based care & & & \\
Proportion of formal care is non-subsidized home-based & 1.144 & & 1.407 \\
care & & & \\
Constant & 3.056 & & 2.387 \\
\hline
\end{tabular}

$\mathrm{N}=870$. selection: families with child(ren) below 3 of FFCS (2004-2005)

Likelihood-ratio test of rho $=0 \mathrm{chi}^{2}(1)=5.206^{* *}$; use correctly predicted: $74 \%$

Significance values * $>90 \% . * *>95 \%$. Log-likelihood $=-451.885$ 
Table 16: Bivariate regression of non-subsidized formal childcare

\begin{tabular}{|c|c|c|c|}
\hline Demand for non-subsidized formal childcare & Coeff. & & Std. Err. \\
\hline Age of the youngest child in months & 0.024 & & 0.052 \\
\hline $\mathrm{Age}^{2}$ & -0.001 & & 0.001 \\
\hline Number of children & -0.237 & $* *$ & 0.081 \\
\hline Age of mother (years) & 0.047 & $* *$ & 0.016 \\
\hline Child with special needs (parental assessment) (0/1) & -0.337 & & 0.431 \\
\hline \multicolumn{4}{|l|}{ Marital status $($ reference $=$ married couple $)$} \\
\hline 2. Single parent & 0.795 & & 0.585 \\
\hline 3. Unmarried cohabition & -0.094 & & 0.153 \\
\hline \multicolumn{4}{|l|}{$\begin{array}{l}\text { Educational level of mother (reference }=\text { up to } \\
\text { primary) }\end{array}$} \\
\hline 3. Secondary school education & 0.533 & * & 0.295 \\
\hline 4. Higher education & 1.185 & $* *$ & 0.322 \\
\hline Family income is below the poverty line $(0 / 1)$ & 3.698 & $* *$ & 1.841 \\
\hline Home owner (0/1) & -0.516 & $* *$ & 0.203 \\
\hline Taxable value of family house (euro) & 0.000 & $* *$ & 0.000 \\
\hline \multicolumn{4}{|l|}{$\begin{array}{l}\text { Maternal grandmother's involvement in paid labor } \\
\text { during childhood of mother (reference = during full } \\
\text { period) }\end{array}$} \\
\hline 2. During part of childhood & 0.113 & & 0.182 \\
\hline 3. Not at all & -0.035 & & 0.189 \\
\hline \multicolumn{4}{|l|}{$\begin{array}{l}\text { Mother's preference of task division with partner } \\
\text { (reference: male breadwinner family) }\end{array}$} \\
\hline 2. Mother with less time-demanding job than father & 0.263 & & 0.221 \\
\hline 3. Partners with equally demanding jobs & 0.367 & $*$ & 0.220 \\
\hline 4. Other & 0.293 & & 0.277 \\
\hline \multicolumn{4}{|l|}{$\begin{array}{l}\text { Father's first choice of childcare service (reference }= \\
\text { father not present) }\end{array}$} \\
\hline 1. Formal care & 0.180 & & 0.172 \\
\hline 2. Informal care & -0.524 & $* *$ & 0.230 \\
\hline 3. Other & -0.048 & & 0.232 \\
\hline Predicted supply of grandparental childcare & -1.335 & $* *$ & 0.481 \\
\hline Predicted supply of subsidized formal childcare & -0.889 & $* *$ & 0.277 \\
\hline \multicolumn{4}{|l|}{ Father's employment (reference $=$ father not present) } \\
\hline 1. Full-time & 1.155 & $* *$ & 0.486 \\
\hline 2. Part-time & 1.112 & $* *$ & 0.529 \\
\hline Constant & -2.679 & $* *$ & 0.860 \\
\hline
\end{tabular}

The following page contains the second part of the estimates 
Table 17: Bivariate regression of non-subsidized formal childcare (continued)

\begin{tabular}{|c|c|c|c|}
\hline Supply of non-subsidized formal childcare & Coef. & & Std. Err. \\
\hline \multicolumn{4}{|l|}{ Belongs to previous table } \\
\hline Mother's age (years) & -0.127 & $* *$ & 0.039 \\
\hline \multicolumn{4}{|l|}{ Marital status $($ reference $=$ married couple $)$} \\
\hline 2. Single & 1.131 & $* *$ & 0.472 \\
\hline 3. Unmarried cohabition & 2.406 & ** & 0.913 \\
\hline Mother is in fair health (self assessed) $(0 / 1)$ & 0.334 & & 0.579 \\
\hline \multicolumn{4}{|l|}{ Mother's educational level (reference $=$ up to primary) } \\
\hline 3. Secondary school education & 0.535 & & 0.478 \\
\hline 4. Higher education & 1.368 & $* *$ & 0.411 \\
\hline Family income is below poverty threshold (0/1) & -2.683 & $* *$ & 0.829 \\
\hline \multicolumn{4}{|l|}{ Type of municipality (reference $=$ residential) } \\
\hline 2. Rural community & 1.378 & $* *$ & 0.399 \\
\hline 3. Economically concentrated or tourist & 0.455 & & 0.291 \\
\hline 4. Semi-urban & -1.436 & $* *$ & 0.363 \\
\hline 5. Urban & 0.154 & & 0.244 \\
\hline $\begin{array}{l}\text { Childcare coverage in municipality (FTE/1000 0-2 year } \\
\text { olds) }\end{array}$ & 4.760 & $* *$ & 1.585 \\
\hline $\begin{array}{l}\text { Proportion of formal care is non-subsidized childcare } \\
\text { centres }\end{array}$ & 1.184 & & 0.862 \\
\hline $\begin{array}{l}\text { Proportion of formal care is non-subsidized } \\
\text { childminders }\end{array}$ & 1.042 & & 0.820 \\
\hline Constant & 1.281 & & 1.404 \\
\hline
\end{tabular}

Significance levels: * >90\%. ${ }^{* *}>95 \%$; Use correctly predicted: $83 \%$

Selection: Families with child(ren) below 3 of FFCS 2004-2005;

$N=870$. Log likelihood $=-347.885 ;$ Likelihood-ratio test of $r$ o $=0$ chi $^{2}(1)=2.779 *$ 
Table 18: Bivariate regression of childcare Demand for any type of childcare

\begin{tabular}{|c|c|c|c|}
\hline Demand for any type of childcare & Coeff & & Std. Err. \\
\hline Age of youngest child in months & 0.205 & $* *$ & 0.041 \\
\hline Age $^{2}$ & -0.006 & $* *$ & 0.001 \\
\hline Number of children & -0.186 & $* *$ & 0.068 \\
\hline Age of mother (years) & -0.045 & $* *$ & 0.015 \\
\hline Child with special needs (parental assessment) (0/1) & -0.527 & & 0.331 \\
\hline \multicolumn{4}{|l|}{ Marital status $($ reference $=$ married couple $)$} \\
\hline 2. Single parent & 1.241 & $* *$ & 0.379 \\
\hline 3. Non-maritally cohabiting & -0.045 & & 0.156 \\
\hline \multicolumn{4}{|l|}{$\begin{array}{l}\text { Educational level of mother (reference }=\text { up to } \\
\text { primary) }\end{array}$} \\
\hline 3. Secondary school education & 0.755 & $* *$ & 0.204 \\
\hline 4. Higher education & 1.290 & $* *$ & 0.190 \\
\hline \multicolumn{4}{|l|}{$\begin{array}{l}\text { Mother's preference of task division with partner } \\
\text { (reference category: male breadwinner family) }\end{array}$} \\
\hline 2. Mother with less time-demanding job than father & 1.004 & $* *$ & 0.195 \\
\hline 3. Partners with equally demanding jobs & 0.936 & $* *$ & 0.188 \\
\hline 4. Other & 0.481 & $* *$ & 0.241 \\
\hline \multicolumn{4}{|l|}{$\begin{array}{l}\text { Maternal grandmother's involvement in paid labor } \\
\text { during childhood of mother (reference }=\text { during full } \\
\text { period) }\end{array}$} \\
\hline 2. During part of childhood & -0.194 & & 0.172 \\
\hline 3. Not at all & 0.033 & & 0.140 \\
\hline Mother's health (self-reported to be "fair". 0/1) & -0.033 & & 0.164 \\
\hline Household income is below the poverty line $(0 / 1)$ & -0.184 & & 0.343 \\
\hline Family is home owner $(0 / 1)$ & 0.021 & & 0.223 \\
\hline Taxable value of the house (euros) & 0.000 & $* *$ & 0.000 \\
\hline \multicolumn{4}{|l|}{$\begin{array}{l}\text { Father's employment status (reference: father not } \\
\text { present) }\end{array}$} \\
\hline 1. Working full-time & 0.848 & $* *$ & 0.223 \\
\hline 2. Working part-time & 0.882 & * & 0.457 \\
\hline Constant & -1.503 & $* *$ & 0.647 \\
\hline
\end{tabular}

Following page contains second part of estimates 
Table 19: Bivariate regression of childcare (continued)

\begin{tabular}{lrrr}
\hline Supply of any type of childcare & Coef. & & Std. Err. \\
\hline Belongs to previous table & & & \\
Age of the youngest child (months) & 0.063 & & 0.042 \\
Age of the child squared (months squared) & -0.002 & $* *$ & 0.001 \\
Number of children & -0.241 & $* *$ & 0.079 \\
Mother's age (years) & 0.079 & $* *$ & 0.019 \\
Child with special needs (parental assessment) (0/1) & -0.107 & & 0.349 \\
Marital status (reference = married couple) & & & \\
2. Single parent & 0.461 & & 0.431 \\
3. Unmarried cohabition & 0.418 & $* *$ & 0.191 \\
Maternal grandmother's involvement in paid labor & & & \\
during childhood of mother (reference $=$ during full & & & \\
period) & & & \\
2. During part of childhood & -0.039 & & 0.183 \\
3. Not at all & -0.386 & $* *$ & 0.140 \\
Mother's educational level (reference $=$ up to primary) & & & \\
3. Secondary school education & -0.268 & & 0.391 \\
4. Higher education & 0.292 & & 0.387 \\
Type of municipality (reference = residential) & & & \\
2. Rural community & 0.194 & & 0.170 \\
3. Economically concentrated or tourist & -0.121 & & 0.161 \\
4. Semi-urban & -0.477 & $* *$ & 0.172 \\
5. Urban & 0.073 & & 0.156 \\
Childcare coverage in municipality (FTE/1000 0-2 year & 2.522 & $* *$ & 0.771 \\
olds) & & & \\
Household income below the poverty line (0/1) & -1.121 & $* *$ & 0.287 \\
Number of grandparents living & 0.243 & $* *$ & 0.072 \\
Grandparental availability index (health. working & -0.108 & $* *$ & 0.046 \\
status. living distance from family home) & & & \\
Constant & -2.441 & $* *$ & 0.916 \\
\hline
\end{tabular}

Significance levels: * >90\%. ${ }^{* *}>95 \%$; Use correctly predicted: $79 \%$

Selection: Families with childr(en) below 3 of FFCS 2004-2005;

$\mathrm{N}=870$. Log likelihood $=-405.554$; Likelihood-ratio test of $\mathrm{rho}=0 \mathrm{chi}^{2}(1)=24.624^{* *}$ 
Table 20: Estimating rationing: descriptives

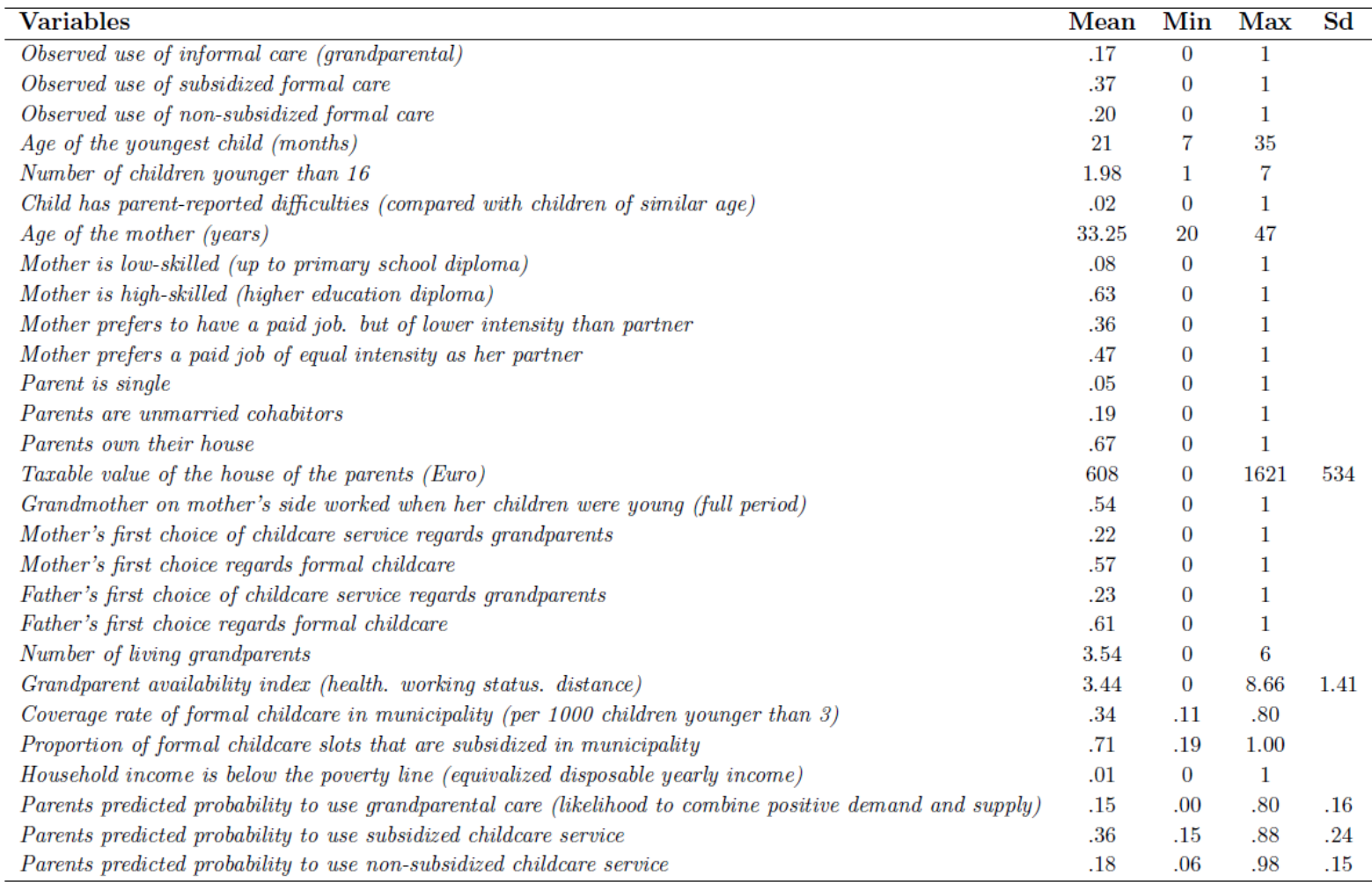

\section{Source: Own Calculations. FFCS (2005)}




\section{Additional tables}

- Descriptives of the sub-sample on which the model is estimated:

Table 21: Descriptive statistics sub-sample

\begin{tabular}{lcc}
\hline & \multicolumn{2}{c}{ Couples } \\
& Mother & Father \\
\hline Average working time/week (hours) & 27.44 & 42.01 \\
Average hourly gross wage & 16.96 & 18.86 \\
Participation (\%) & 80.66 & 100 \\
Average age & 33.25 & 36.78 \\
University degree (\%) & 62.70 & 49.22 \\
Presence of child 0-3 (\%) & \multicolumn{2}{c}{100} \\
Presence of child 4-6 (\%) & \multicolumn{2}{c}{37.70} \\
Presence of child 7-9 (\%) & \multicolumn{2}{c}{15.23} \\
Presence of child 10-12 (\%) & \multicolumn{2}{c}{4.18} \\
Presence of child 13-15 (\%) & \multicolumn{2}{c}{512} \\
Amount of observations & \multicolumn{2}{c}{512} \\
\hline
\end{tabular}

Source: FFCS (2005). own calculations

- Wage regression in order to be able to derive gross labor income at each discrete labor supply point:

Table 22: Hourly wage regression women

\begin{tabular}{lcc}
\hline Dependent variable: In hourly wage & Coeff. & Std. error \\
\hline Age & & \\
Age squared & .00231 & .032160 \\
Civil servant & .00011 & .000486 \\
Experience & .05576 & .037624 \\
No degree & $.000034^{*}$ & .000796 \\
Primary degree & $-.37787^{*}$ & .158335 \\
Low secondary degree & $-.60236^{*}$ & .175674 \\
High secondary degree & $-.49724^{*}$ & .056266 \\
Constant & $-.23731^{*}$ & .031096 \\
\hline
\end{tabular}

*Significant on $5 \%$ level

Source: Own Calculations. FFCS (2005) 